\title{
Anti-oxidative Effects of Melatonin in Protection Against Renal tubular Damage Caused By Ionizing Radiation In Mice (Histological and electron microscopical studies)
}

\author{
Hanaa Fathy Waer \\ Biology Depart. Histology Lap. National center for radiation Research and technology \\ Atomic Energy Authority, Cairo
}

\begin{abstract}
The response to ionizing radiation, at the cellular level, depends on a number of factors that may be grouped into those that are genetically controlled, radiation quality, dosage, and environmental factors. The biological effects of low levels of ionizing radiation, and regulatory measures to protect people from exposure to low doses, have come in for much scrutiny in recent years.

The objective of this study is to examine the potential radioprotective properties of melatonin in exposed low dose irradiated mice. Kidney, is selected to study the effect of low dose gamma irradiation as it is a target organ of many other organs, which influence its function. Histopathological, and electron microscopical changes of the renal tubular structure of the kidney were studied in irradiated, and melatonin treated animals. Male adult albino mice were used in this experiment, they were divided into 5 main groups: the first was, served as control normal group. The $2^{\text {nd }}$ was given-in a fractionated dose of gamma radiation at a dose level $(1 / 2$ Gy) twice a week for eight weeks, while the third were left 8 more weeks without radiation. The $4^{\text {th }}$ group was given daily intraperitoneal, i.p. $10 \mathrm{mg} / \mathrm{kg}$ melatonin and irradiated by $1 / 2$ Gy twice a week for eight weeks, and the $5^{\text {th }}$ was left 8 more weeks given melatonin only without irradiation. (All groups of animals were scarified at two time intervals 8 and 16 weeks). It could be observed that The intensity of the histological damage was more marked in the untreated irradiated group which irradiated for 8 weeks than those which are irradiated and left 8 more weeks without radiation irradiated. Hydropic change in the renal tubule, degenerative, narcotizing changes, and areas of complete proximal tubular necrosis and autolysis break down were detected.

The protection offered by pretreatment with Mel. is particularly dramatic. . The proximal tubules retain its normality and structure; the nuclei were rounded with welldeveloped nuclear membrane and chromatin. On the other hand the distal tubules were well designed with many mitochondria and healthy nucleus. It could be reported that 10 $\mathrm{mg} / \mathrm{kg}$ melatonin given Intraperitoneal, (i.p.) Daily to the irradiated animals helped very much the kidney to be protected from radiation injuries.

The radioprotective effects of melatonin against cellular damage caused by radiation oxidative stress and its low toxicity make it a potential supplement in the treatment or co-treatment in situations where the effects of ionizing radiation are to be minimized.
\end{abstract}




\section{Introduction}

We are constantly exposed to low levels of radiation from outer space, earth, and the healing arts. Low levels of naturally occurring radioactive mat erial are in our environment, the food we eat, and in many consumer products. Some consumer products also contain small amounts of man-made radioactive material. All exposures to presumed to increase the risk of cancer. The amount of increased risk is proportional to exposure.

Some of the effects of low doses of radiation could thus appear to be analogous to the effect called "horm esis" which some chemicals are known to exhibit in living organisms. At trace levels, these chemical agents are necessary and/or beneficial to life but, at high levels, they are poisonous. Small increases may be beneficial, large increases may be fatal (Luckey, 1991 and Parsons 1994.)

Referred to Kellerer et al., (2002), The effects of low doses and low dose rates may be bio-positive or they may be bio-negative. They may vary from cell to cell, between different organs of the body and from person to person. Halliwell and Aruoma, (1991), Morgan et al., (1996), and Wallac, (1998) stated that when ionizing radiation interact with living cells, it causes a variety of changes depending on exposed and absorbed dose, duration of exposure and interval after exposure, and suscept ibility of tissues to ionizing radiation. The sensitivity of cells to ionizing radiation depends especially on the rate of differentiation and accompanying factors of the tissue as well as on the efficiency of the intrinsic anti- oxidative defense systems Maisin, (1982) represented that mice irradiated with 13.5 Gy or more affects very much the tissue. The tissues most affected are the kidney and the lymphoid tissues. Donaldson et al., (1984) found that animals received 1000-rad singlefraction radiation and sacrificed at 3 and 24 weeks after irradiation exhibited renal growth inhibition without body growth inhibition, and renal functional abnormalities including elevation of serum blood urea nitrogen and reduction of glomerular filtration rate. Regarding this Rojas et al., (1986) declared that fractionated X-ray treat ment on kidney might cause anaplastic murine tumor.

Geraci et al., (1990) reported that kidney injury was judged to be the primary cause of death of all 15 - and 20-Gy thorax-irradiated animals. Animals with kidney damage had elevated PUN and reduced 51Cr-EDTA clearance and hematocrits. Koultca venia, (1998) come to the fact that kidneys of irradiated rats that received 0 to 17 Gray total body irradiation showed glomerular tuft capsular adhesions and hyalinization, focal tubular necrosis, severe interstitial fibrosis, and marked thickening and hyaline degeneration of the wall of interlobular arteries and arterioles, with intimal proliferation and periadventitial edema and inflammation.

Safwat et al., (1995) study renal damage after total body irradiation they found that animals given at two different dose rates either high dose rate (HDR;0. $71 \mathrm{~Gy} / \mathrm{min}$ ) or low dose rate (LDR;0. 08Gy/min) caused renal damage in $50 \%$ of irradiated animals. On the other hand Singh, et al., (1998) realized that whole body irradiated mice (Co-60 Gamma-ray, absorbed doses of 2.5 to 10 Gy delivered at dose rates of 0.01 to $0.50 \mathrm{~Gy} / \mathrm{min}$ ) induced chromo somal aberrations, micronuclei forma tion, alterations in DNA content 
dispersion, impairment in the kidney function.

van Kampen et al., (2003) investigate the role of irradiated volumes at intra-operative radiation therapy in the development of ureteral injury in dogs, they found that the irradiated parts of the uòeters in all dogs showed abnormal histopathologic findi ngs, such as fibrosis. While Lindholt , (2003) declared that. X-ray examination is still the third leading cause of hospital-acquired acute renal failure. The cause is a hypoxic tubular injury due to vasoconstriction with release of free oxygen radicals.

Melatonin (Mel) is the chief secretary product of the pineal gland and has a very potent antioxidant activity, depending mainly on its capacity to act as electron donor (Tan, et al., 1993 and Reiter, 1995). In vivo and in vitro, Mel has been found to protect tissues against oxidative damage generated by a variety of toxic agents and metabolic processes, including chemotherapy-induced toxicity (Lissoni et al., 1997) and ischemia-reperfusion injury in stomach, liver, and brain (Sewerynek et al., 1996, De Lastra et al., 1997, and Konturek et al.1997). More pertinently. Mel has recently been found to protect against adriamycininduced nephrotoxicity Mel. is widely available, relatively free of side effects, rapidly active after oral administration, and commonly used in humans in the treatment of insomnia (Brzezinski, 1997).

Studies on the protective effects of melatonin against damage caused by ionizing radiation began soon after the discovery of its antioxidative properties. Actually, the first study that revealed the anti-oxidative effects of melatonin to a physical agent was conducted using ultraviolet light (UV), which shares many features with ionizing radiation.
Tan et al., (1993) reported that melatonin scavenges ${ }^{\circ} \mathrm{OH}$ generated in vitro when $\mathrm{H}_{2} \mathrm{O}_{2}$ was exposed to ultraviolet light. In vivo as well, UV light damage to the skin is known to be prevented by melatonin. Using a similar model, the potency of melatonin in protecting against ${ }^{\circ} \mathrm{OH}$ generated by ionizing radiation was confirmed under in vivo conditions (Tan et al., 1998). In the meantime, a number of studies have tested melatonin's efficacy in the protection against ionizing radiation both in vivo and in vitro.

Mayerly et al., (2000) stated that Melatonin,N-acetyl-5-methoxytryptam ine, is a well-known antioxidant that protects DNA, lipids, and proteins from free radical damage. A recent study evaluated the effect of melatonin, a potent free radical scavenger, on mercury-induced kidney failure. It prevented an increase in kidney content of malondialdehyde (MDA, stress marker) and decrease in glutathione (GSH) resulting from mercury toxicity. Melatonin also induced an important reduction in super oxide-positive cells. Thus, the beneficial effects of pharm acological doses of melatonin in kidney disease are due to its antioxidant prop erties Maigorzata and Russel ,(2000), reported that, Ionizing radiation is a potent carcinogen, and its injury to living cells is, to a large extent, due to free radical stress. DNA is the molecule most often damaged by ionizing radiation. Hydroxyl radicals $(\mathrm{OH})$ considered the most damaging of oil free radicals generated in organisms. The radio protective effects of melatonin against cellular damage caused by free radicals and its low toxicity make melatonin a treatment or co treatment when minimizing the effects of ionizing radiation. Parlakpinar et al., (2002), executed that the damage in the kidney induced by radiation was 
reversed by melatonin. The results showed that pharmacological and phys iological concentrations of melatonin reduce radiation-induced renal injury.

\section{Material And Methods:}

Studies were done in 60 male mice, weighing 20-25 gm and fed on a standard mice chow and watered ad libitum. Animas were divided equally into five groups: The first group served as a control normal group The second group, animals were given a fractionated dose of gamma radiation at a dose level ( $1 / 2$ Gy) twice a week for eight weeks. While, the third group were given fractionated dose of gamma radiation at a dose level ( $1 / 2$ Gy) twice a week for eight weeks then left for 8 more weeks without radiation. A Cesium-137 ventilated Gamma Cell-40 belonging to the National Center for Radiation Research and Technology (NCRRT), at a dose rate $1 \mathrm{~Gy} / 1.5 \mathrm{~min}$, performed radiation. The fourth group was radiated and treated group, animals were given daily the recommended melatonin dose daily $(10 \mathrm{mg} / \mathrm{kg}$ i.p. $)$ melatonin and irradiated by $1 / 2$ Gy twice a week for 8 weeks. While the fifth group was given daily the recom mended melatonin dose daily $(10 \mathrm{mg} / \mathrm{kg}$ i.p.) melatonin and irradiated by $1 / 2 \mathrm{~Gy}$ twice a week then, left 8 more weeks given melatonin only with out irradiation.

(All groups of animals were scarified at two time intervals 8 and 16 weeks).

Histological and Electron microscopic preparations:

Specimens of kidney were fixed in Bouin's fluid for preparation of paraffin blocks. Sections were made at $5 \mu$ thicknesses and stained with Haematoxylin and Eosin (Mallory, 1944).
Semi thin sections with a thickness of 1 $\mu \mathrm{m}$ were performed for more unequivocal identification and stained with Toluidine blue and evaluated under light microscope at 400x and 1000x magnifications. (Luft, 1961). Ultra-thin sections were prepared according to Reynold, (1963) and examined under the

\section{Results:}

\section{Light Microscopic studies}

1-Haematoxylin and eosin staining:

The renal cortex of the control normal group showed general arrang ement of glomeruli and tubules. Bowman's capsule surrounds each glomerulus. The glomerular tuft cons ists of a network of endothelial-lined capillaries with a thin basement memb rane. The tubules, mainly proximal convoluted, are lined by a single layer of cuboidal or low columnar epithelium. (Figs 1 \& 2).

Examined sections of the renal cortex that were exposed to fractionate dose of gamma radiation showed that the intensity of the histological damage was more marked in the irradiated group which irradiated for 8 weeks than those which are irradiated and left more 8 weeks without radiation. The kidney tissue sections of 8 weeks irradiated mice showed degenerative and narco tizing changes. Areas of complete proximal tubular necrosis and autolysis break down with disruption of the tubular basement membrane were seen (.Fig 3). Also, a hydropic change in the renal tubule, disturbance of the inter lobular space many inflammatory cells in the adjacent interstitium and affected arteriole were observed (Figs 4 \& 5).

A prominent feature in the 16 weeks irradiated mice where half of the animals were left 8 more weeks without radiation was that the renal cells could not retain its normality. Extreme 
hydropic change in the renal tubule, mild interstitial edema could be observed. Reduction of the extension of completely necrotic tubules was reduced (Figs 6 \&7).

Treatment of both groups four and five with melatonin markedly improved histological damage. (Figs 8,9) reviles, some of the tubules restored its normal structure, while small area of inflammatory cells infiltration were detected.

**Toluidine blue staining (semi-thin sections):

Semi thin sections of normal control kidney showed a well-organized distal and convoluted tubule (fig 10). In the irradiated mice the examined semi thin sections showed variable changes these changes were manifested as cloudy swelling and disorganization of the tubules (Fig 11). Examined sections that irradiated and left 8 weeks without irradiation showed mild improvement as there are enlargement of the urinary spaces, necrotic area and strongly acidophilic cytoplasm The vascular spaces are widely dilated (Fig 12).

Semi thin section of melatonin treated animals of group 4, showed cloudy swelling and hydropic degeneration still observed in some parts (fig 13) while other parts showed markedly improvement (Fig 14).

On the other hand examined sections from group 5 that treated for more 8 weeks without radiation showed normal structure of both distal and convoluted tubule (Figs15\& 16).

Eleetron microscopic studies:

Examined sections of kidneys of a normal control mice (proximal convoluted and distal convoluted tubule) showed well organization. The proximal convoluted tubule (PCT) cells reveal prominent brush border (BP), large rounded nucleus, and., many rounded mitochondria with elongated cristae (M) (Fig 17, 18) .The distal convoluted tubule (DCT) found with few microvilli in the apical surface, the cytoplasm had many mitochondria (M), with oval and rounded nuclei (Fig. 19). Electron microscopic examination of sections of 8 weeks irradiated kidneys reviled many degenerative changes in the proximal and distal tubules the proximal tubules were seen with damaged lining cells, deteriorated and vacuolated cytoplasm. Apical plasma membrane and, microvilli. It could be easily observed that the cell junction were also disturbed the mitochondria is fragmented and randomly oriented with damaged cristae and the cytoplasm become deteriorated with various vacuoles sizes, the endoplasmic reticulum was disorganized, ruptured and almost disappeared the mitochondria was greatly damaged and lost its regular shape the nuclei became amorphous and lake there heterochromatine lipid droplets with large sizes, fat, lipid granules with large sizes and damaged mitochondria with bizarre shape and tendency to fusion could be observed.

Higher magnification reviles changes of the basement membrane that is markedly devoid of basal folding. (Figs 20, 21, 22).

The sections from mice kidneys (renal proximal and distal convoluted tubules) that irradiated for 8 weeks and left 8 more weeks without exposure showed that mild amelioration could be observed. The brush boarder of the renal proximal tubule was still lost and the ground cytoplasm was disorganized and vacuolated, the nucleus was more rounded and the nuclear envelope could easily detected, the endoplasmic reticu lum is fragmented and the lining cells of the distal tubules appear markedly rarified .The mitochondria were small and electron dense( Figs 23, 24 ,25,26) 
In the Examined sections that given daily the recommended dose of melatonin and irradiated twice a week $(1 / 2 \mathrm{~Gy} /$ week) for 8 weeks and those that left 8 more weeks given Mel. Only without irradiation showed that melatonin greatly protected the cells and ameliorate the radiation injuries that may happen after radiation exposure. The proximal tubules retain its normality and structure; the nuclei were rounded with well-developed nuclear membrane and chromatin. The basement membranes regain its structure with distinct brush border and precipitated plasma protein was

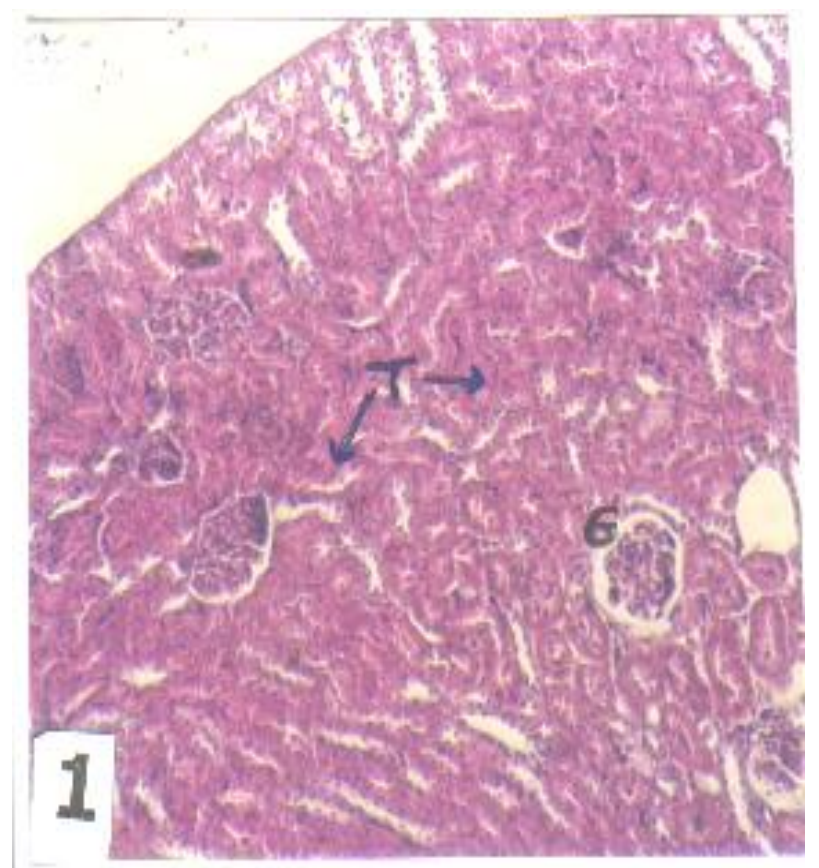

Fig 1 -A photo micrograph of a section from normal mouse kidney showing general arrangement of glomeruli (G) and tubules (T). (200x H\& E) recognized. On the other hand the distal tubules were well designed with many mitochondria and healthy nucleus while the cytoplasm was still vacuolated and darkly stained in some parts than the others (.Figs 27, 28)

On the other hand, examined sections of irradiated kidneys that treated for 8 weeks and left 8 weeks more treated without radiation showed the treatment of melatonin after and before irradiation helped the cells of the kidney to be more or less normal in structure. Small effects still observed and could be summarized by cytoplasmic vacuolation and myelin patches (Fig, 29, 30, 31).

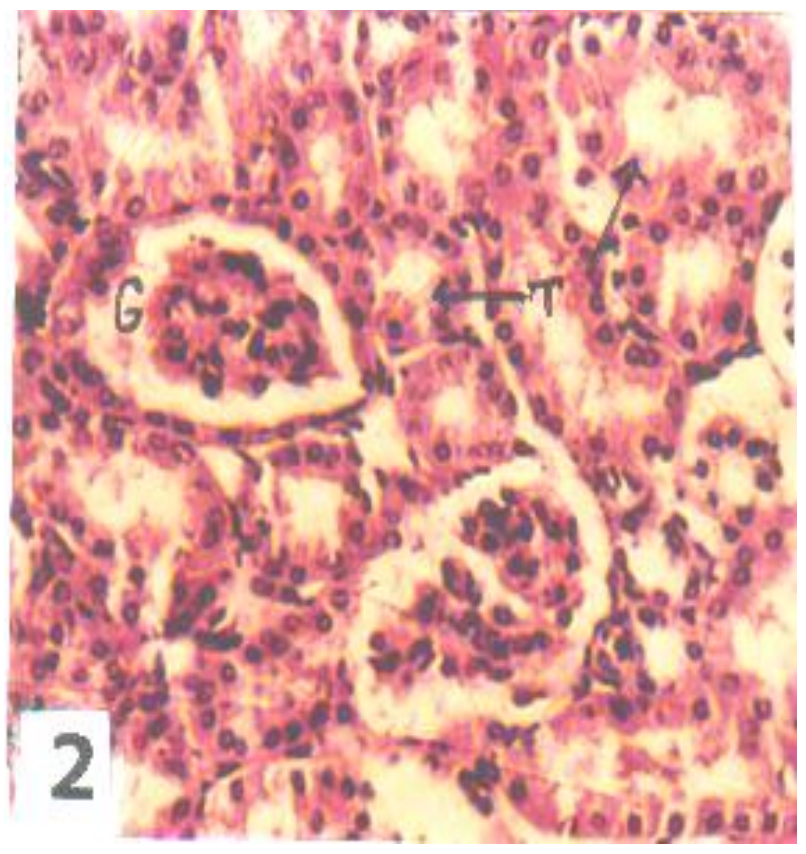

Fig 2 A photo micrograph of a section from normal mouse kidney showing that The tubules, mainly proximal convoluted, are lined by a single layer of cuboidal or low columnar epithelium. (400x H\&E) 


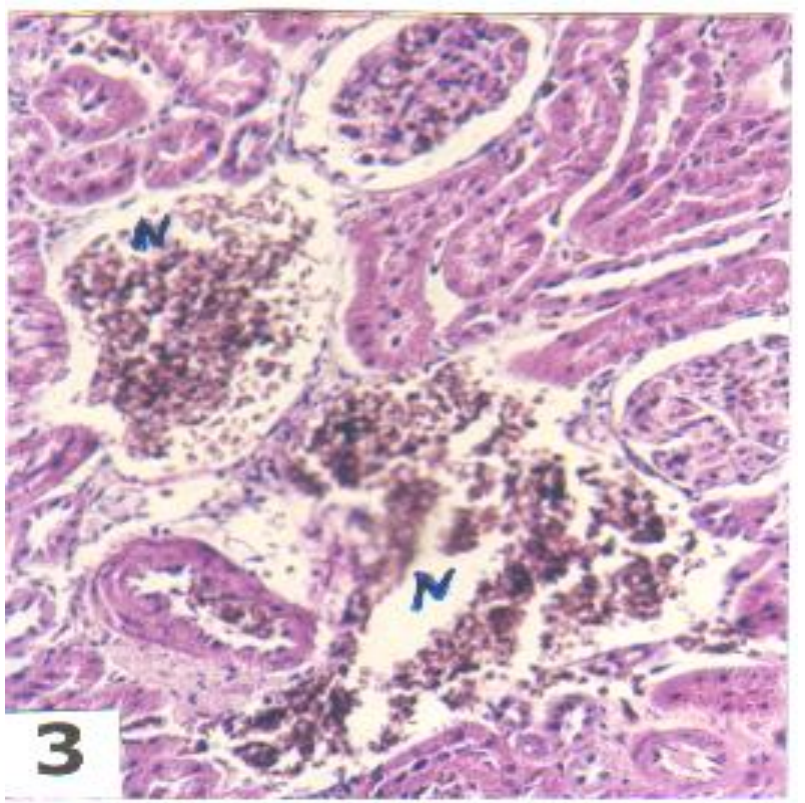

Fig 3. A photomicrograph of a section from irradiated mouse kidney showed hydropic change in the renal tubuleand area of necroses $(\mathrm{N})$. (400x H\&E)

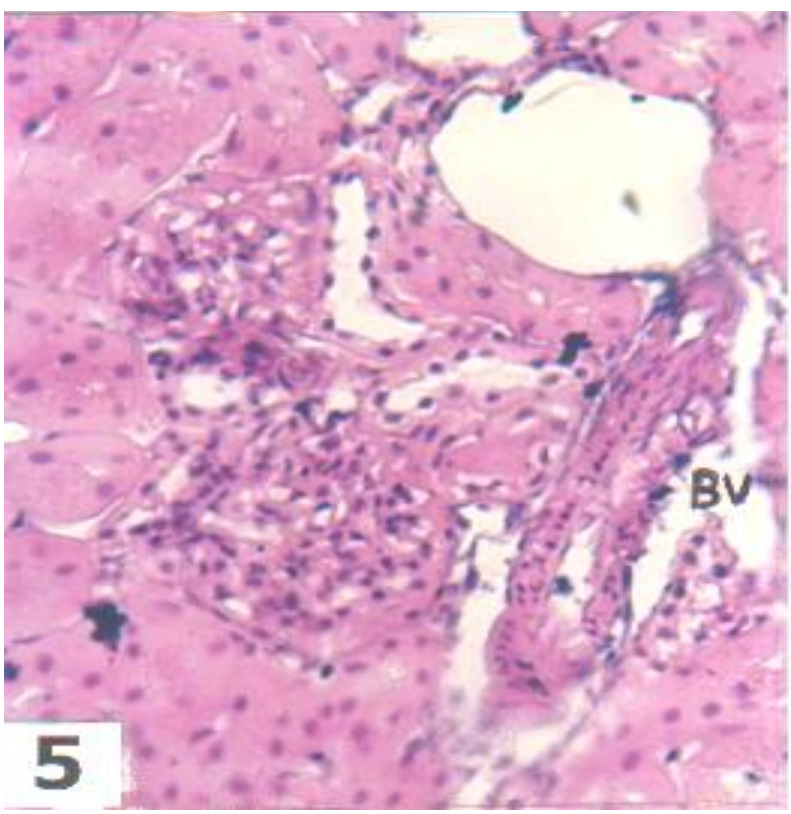

Fig 5 - A photo micrograph of a section from irradiated mouse kidney showed many inflammatory cells in the adjacent interstitium and thickening of blood vessel (BV) . (600x H\&E)

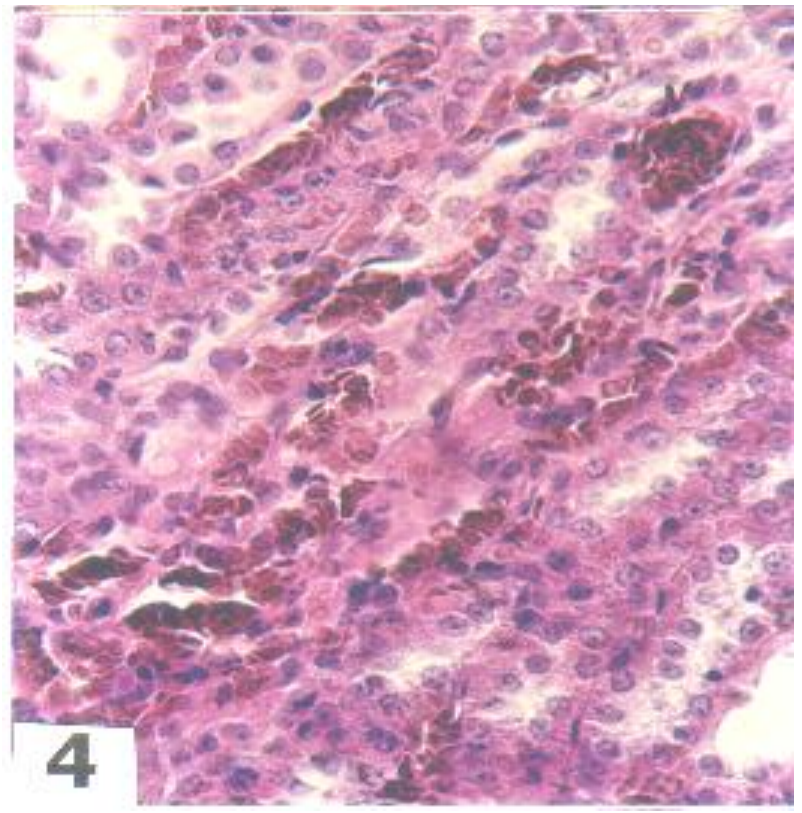

Fig 4 -A photomicrograph of a section from irradiated mouse kidney. Some necrotic cells, which characterized by areas of proximal tubular necrosis and autolysis break down with disruption of the tubular basement membrane were seen (400x H\&E)

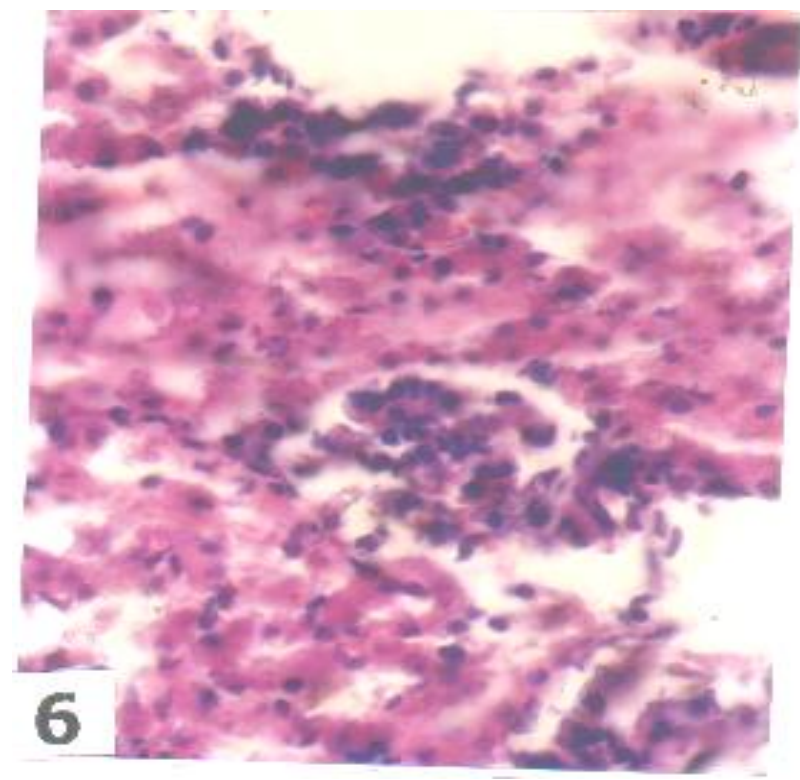

Fig 6 - A photomicrograph of a section from irradiated mouse kidney that left 8 more weeks without radiation showing extreme hydropic change in the renal tubule and mild interstitial edema (600x H\&E) 


\section{Hanaa Fathy Waer}

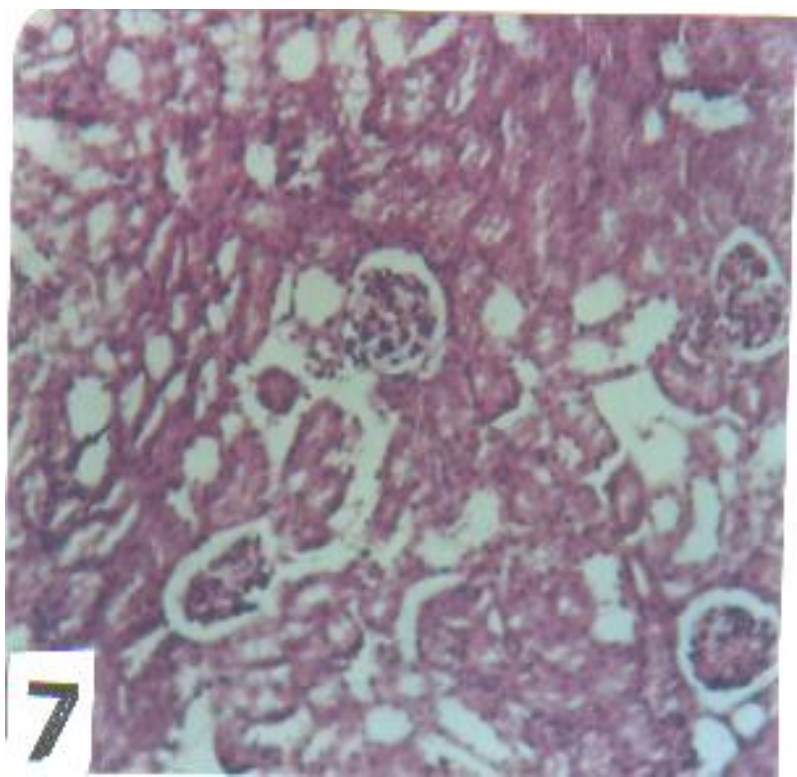

Fig 7 -A photomicrograph of a section from irradiated mouse kidney that left 8 more weeks without radiation showing reduction of the necrotic tubular cells and moderate degeneration. (400x H\&E)
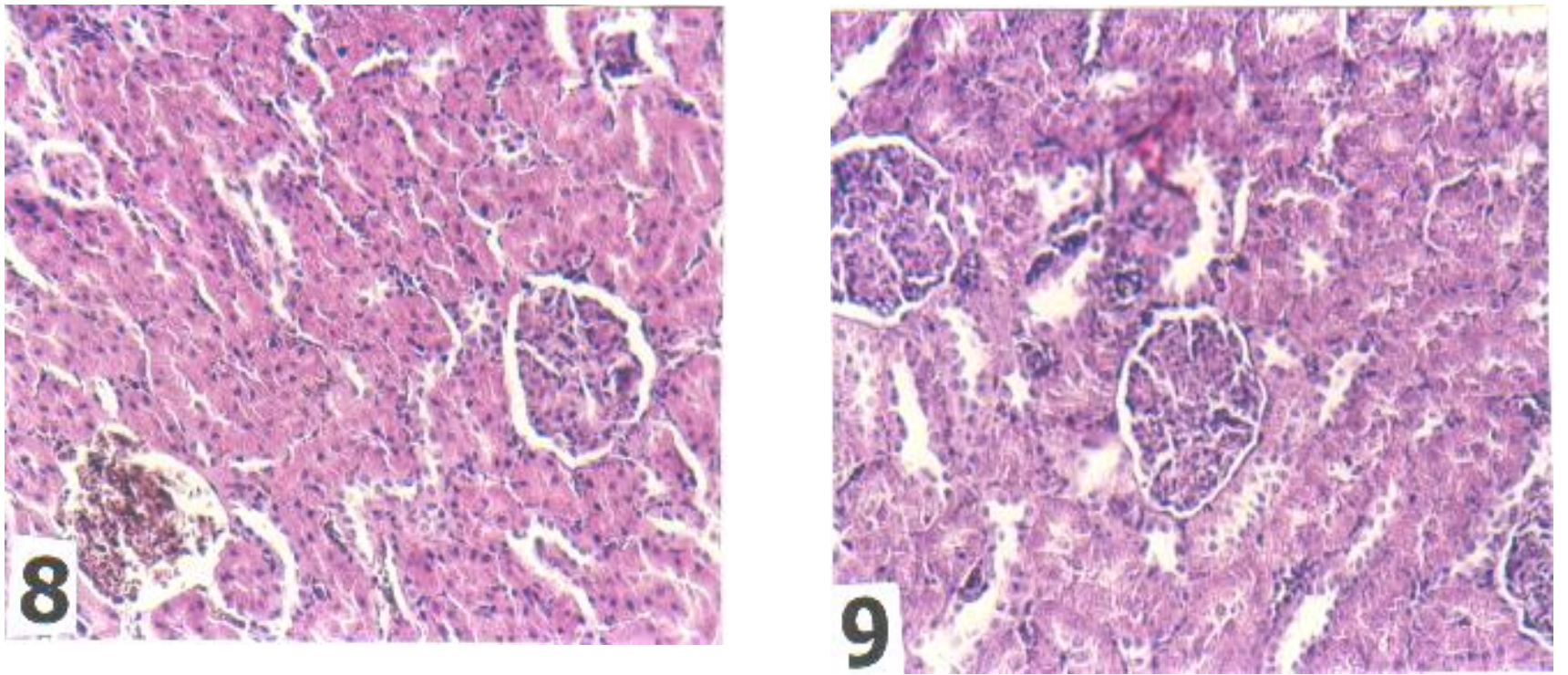

Figs $(8,9)$ - A photomicrographs of a section of kidney from treated animal showed that, Mel markedly improved histological damage. Treatment. Notice, normal structure of the tubules while small area of necroses is still observed. (400x H\&E) 


\section{Anti-oxidative Effects of Melatonin in Protection......}

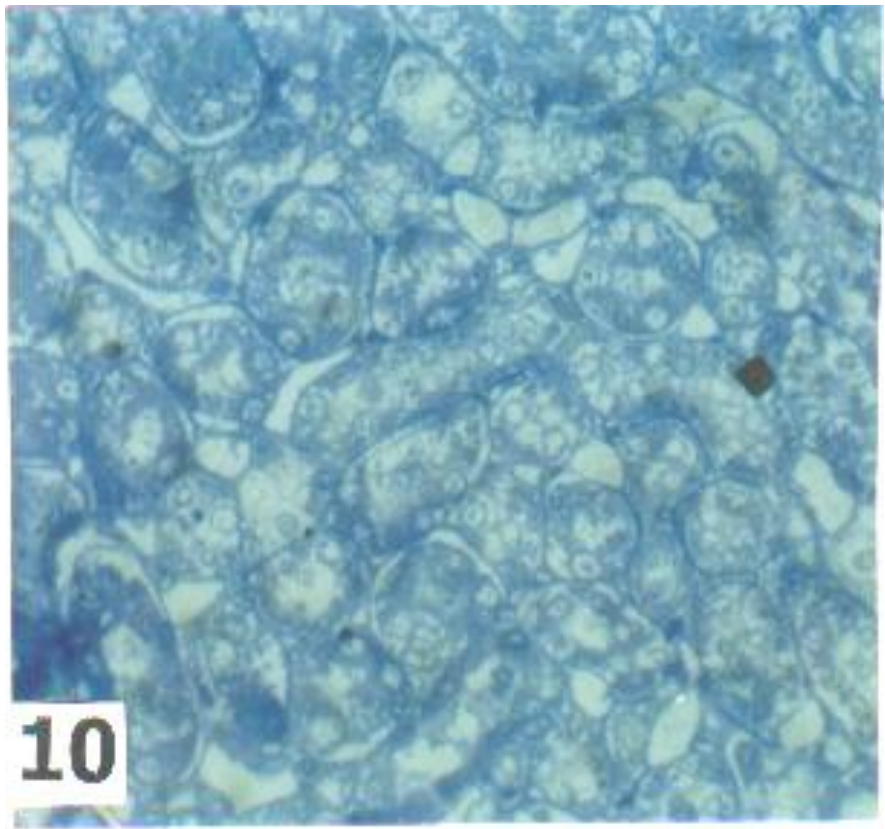

Fig 10 - A photomicrograph of a semi thin section from normal mouse kidney showing a well-organized distal and convoluted tubule (toluidine blue 1000x)

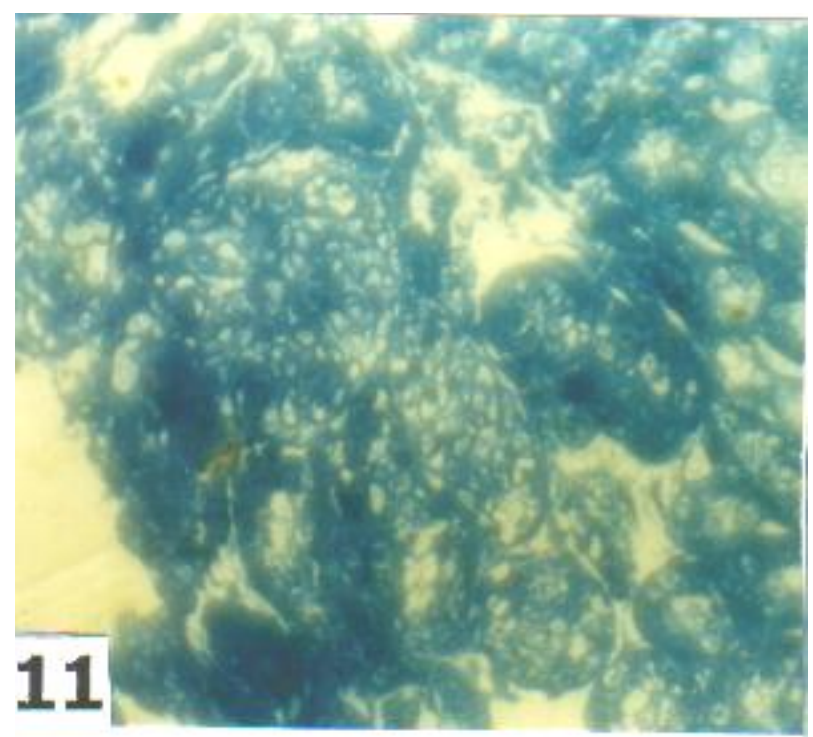

Fig 11 A photo micrograph of semi thin section of irradiated mouse kidney of group 2 showed variable changes these changes were manifested as cloudy swelling and disorganization of the tubules (toluidine blue $1000 x$ )

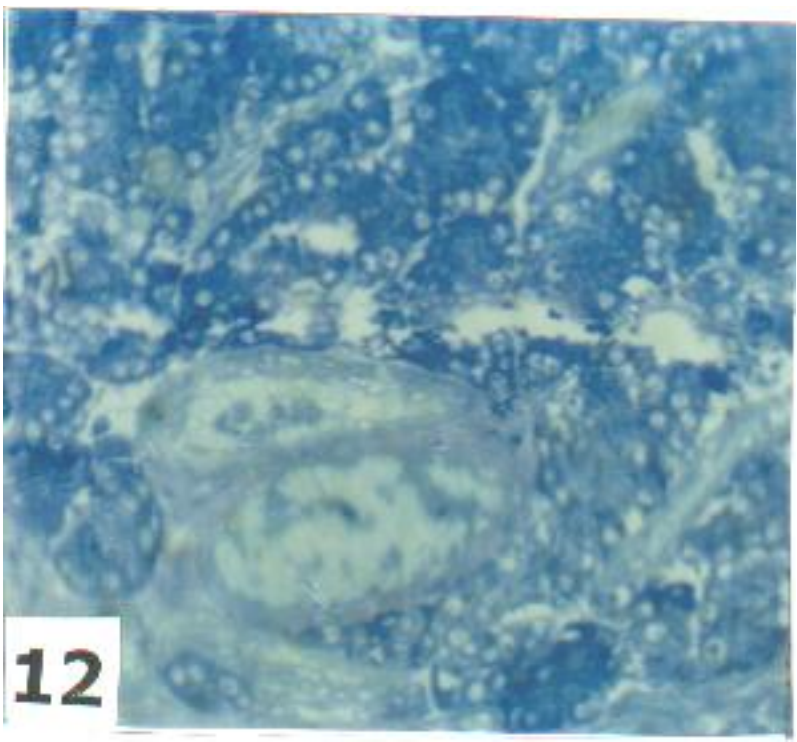

Fig 12. A photomicrograph of semi thin, Seetion from kidney irradiated mouse kidncy of group 3, showed mild improvement, (toluidine blue 1000x) 


\section{Hanaa Fathy Waer}
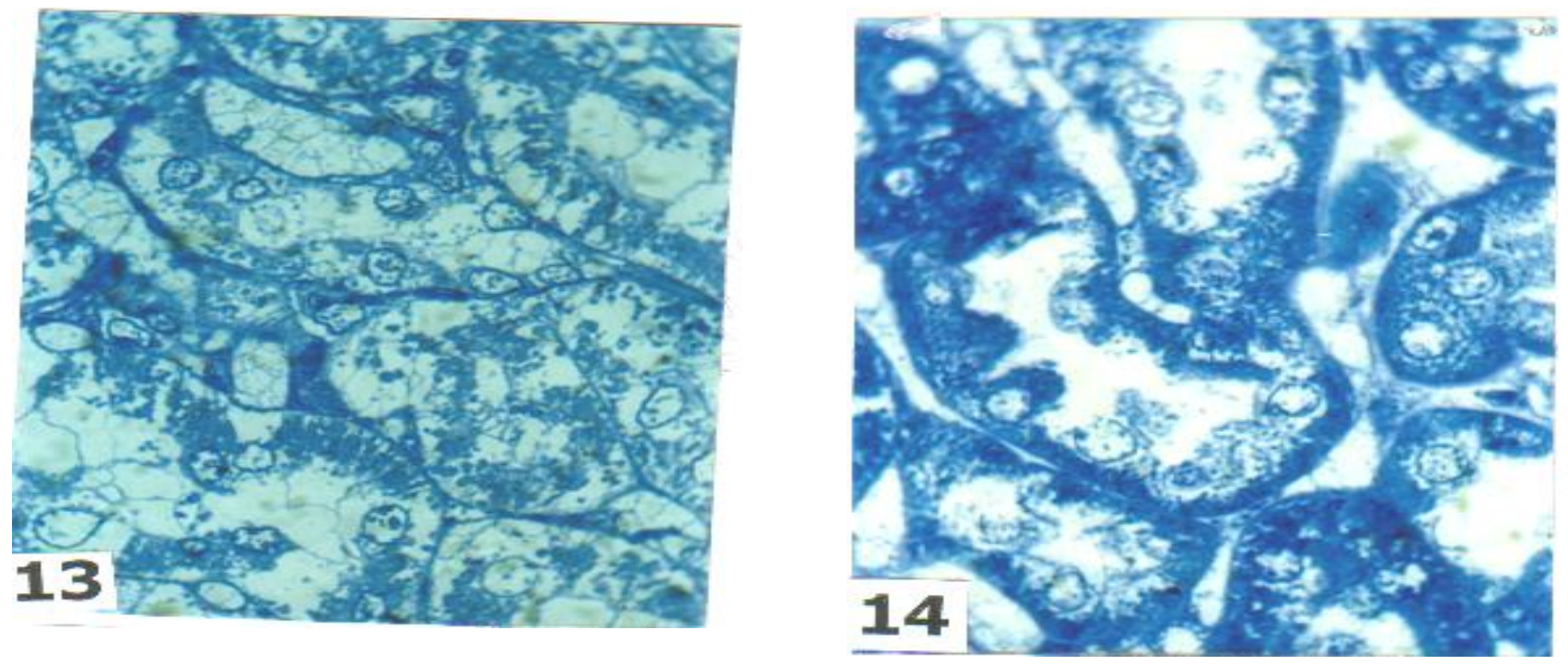

Fig s 13, 14: photomicrographs of semi thin kidney section of treated mouse of group 4 notice a markedly improvement by Mel. treatment (toluidine blue 1000x)
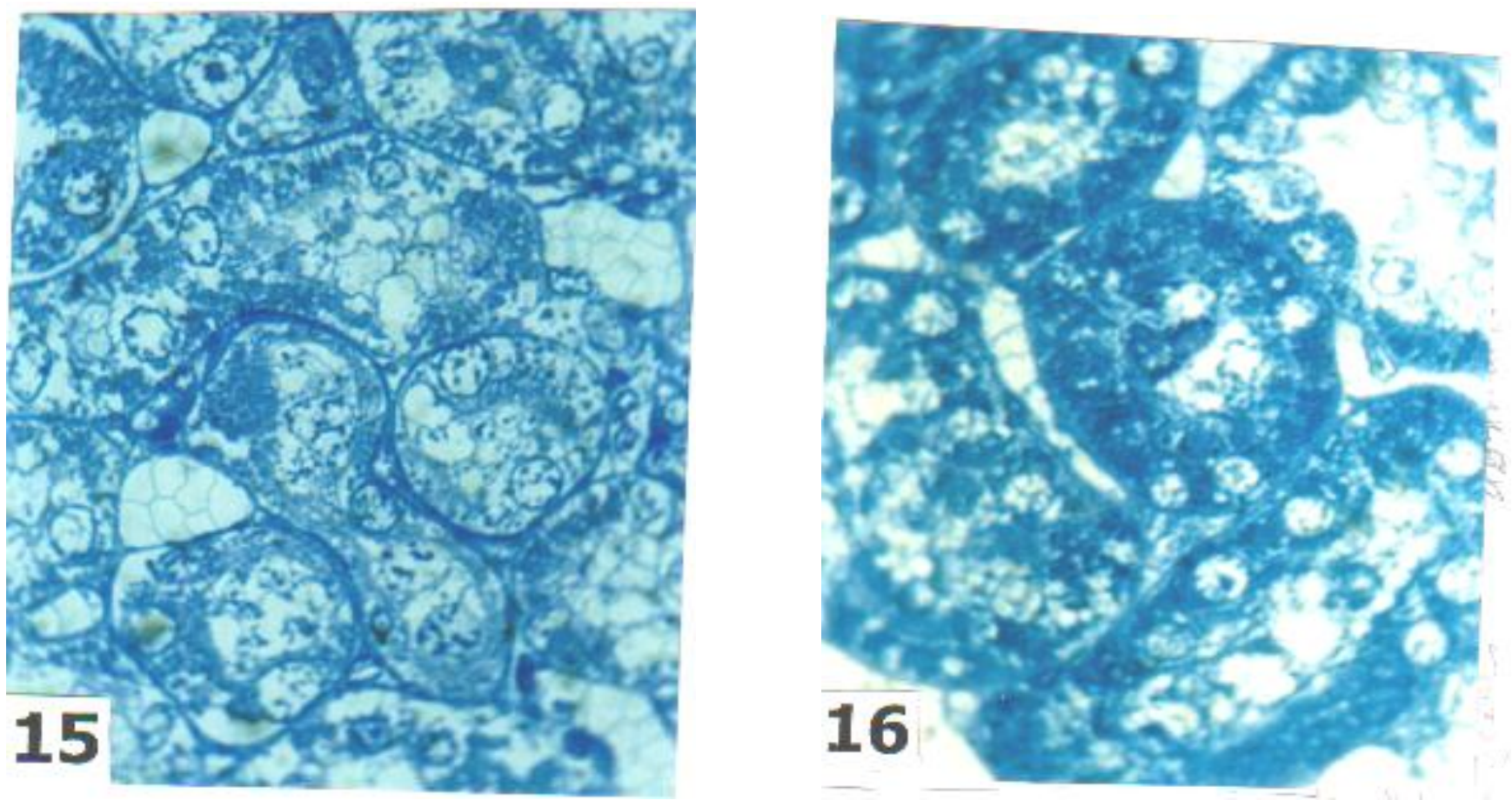
Figs $15 \& 16$ : A photo t micrograph of semi thin kidney section of Met treated mouse of group 5 showed swallowed but healthy tubules both distal and convoluted tubule was well organized with distinct brush border and microvilli. (Toluidine blue 1000x)
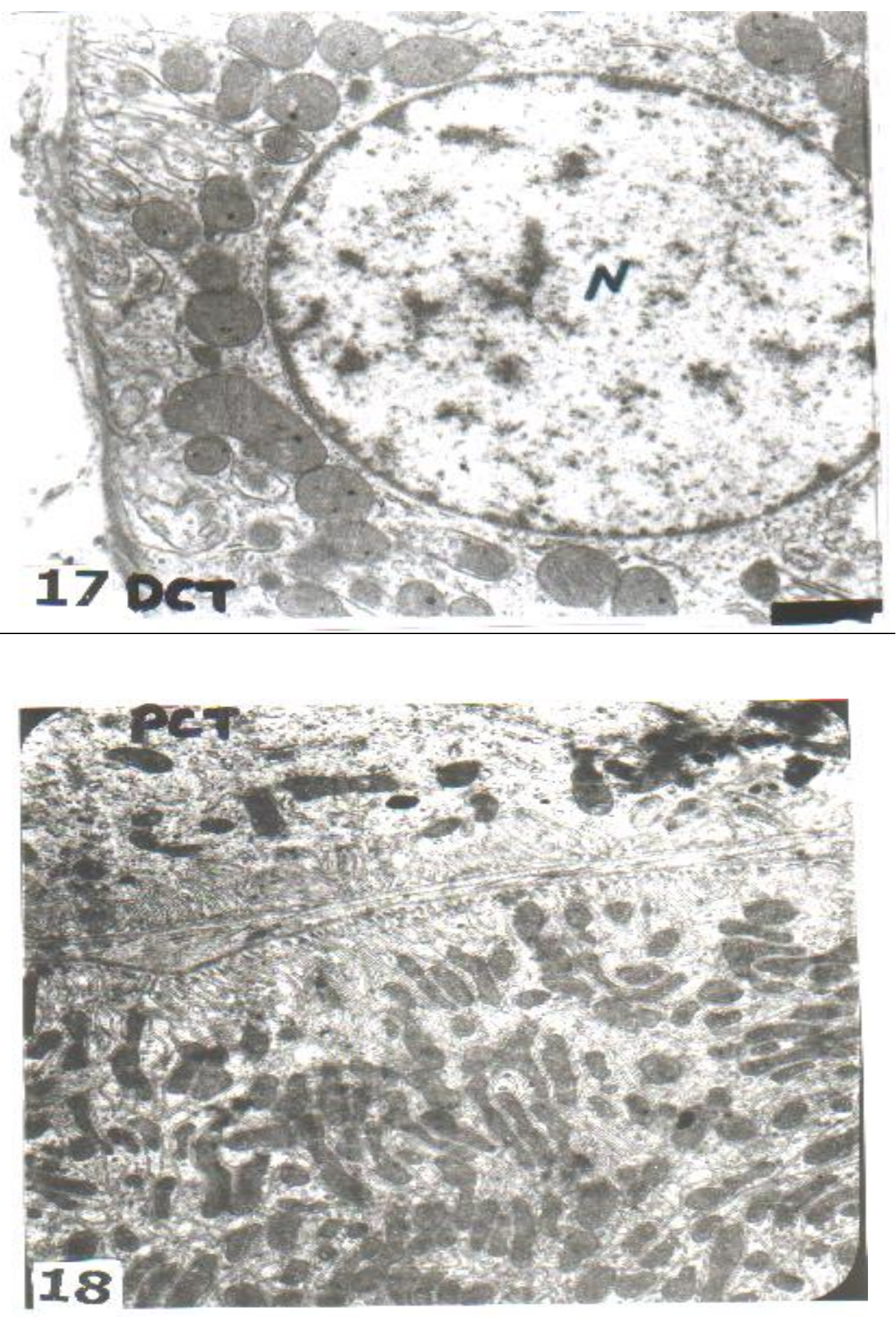
Fig 17, 18: Electron micrographs of a section of normal control mouse kidney showed distal (DCT) and proximal convoluted tubule (PCT) cells reveal prominent brush border (BP), large rounded nucleus, and., many rounded mitochondria with elongated cristae (M).

( 6000X \& 40000X)

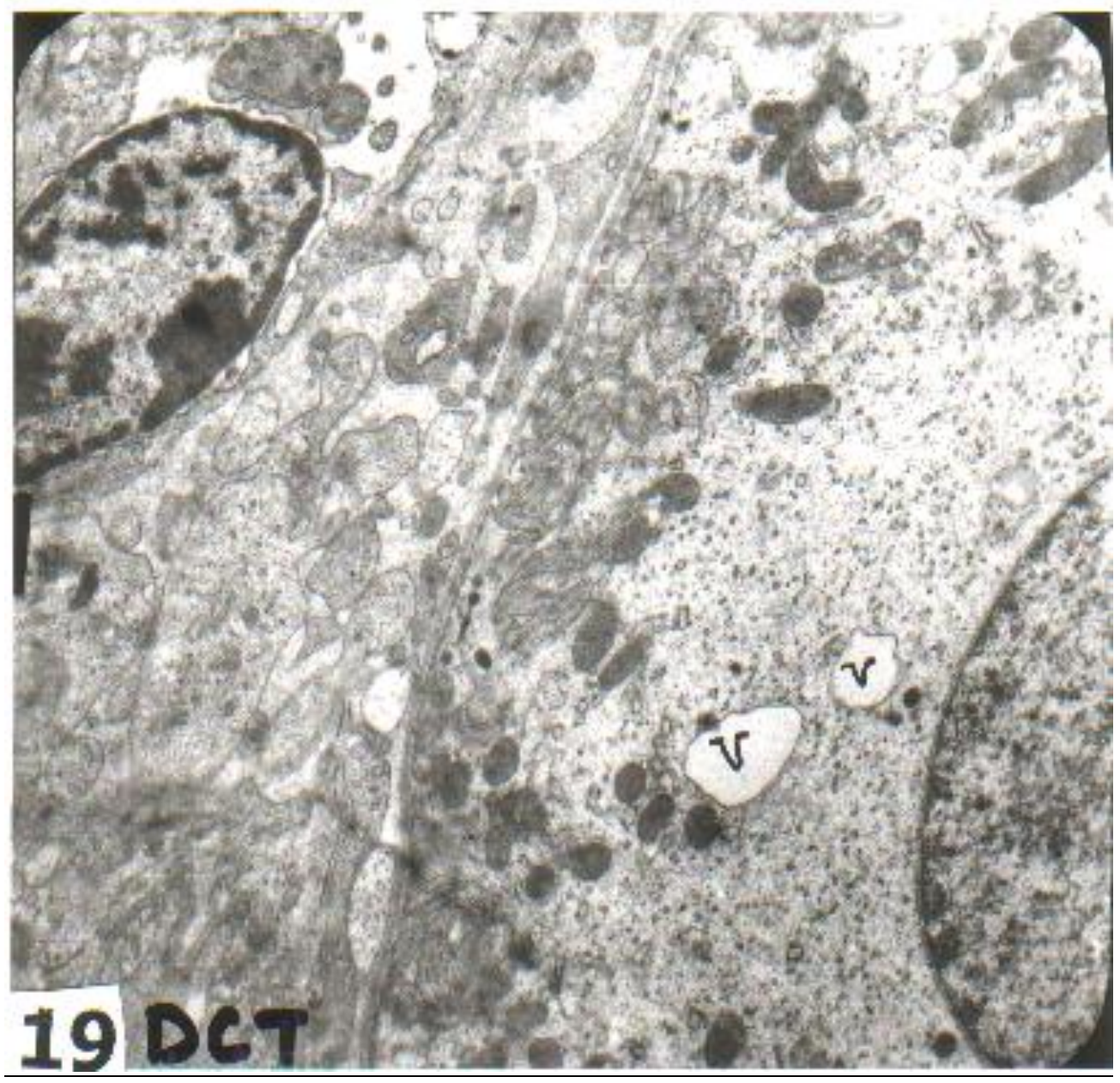

Fig 19: Electron micrograph a section of normal control mouse kidney the distal convoluted tubule (DCT) found with few microvilli in the apical surface, the cytoplasm had many mitochondria (M), with oval and rounded nuclei. (40000 X ) 

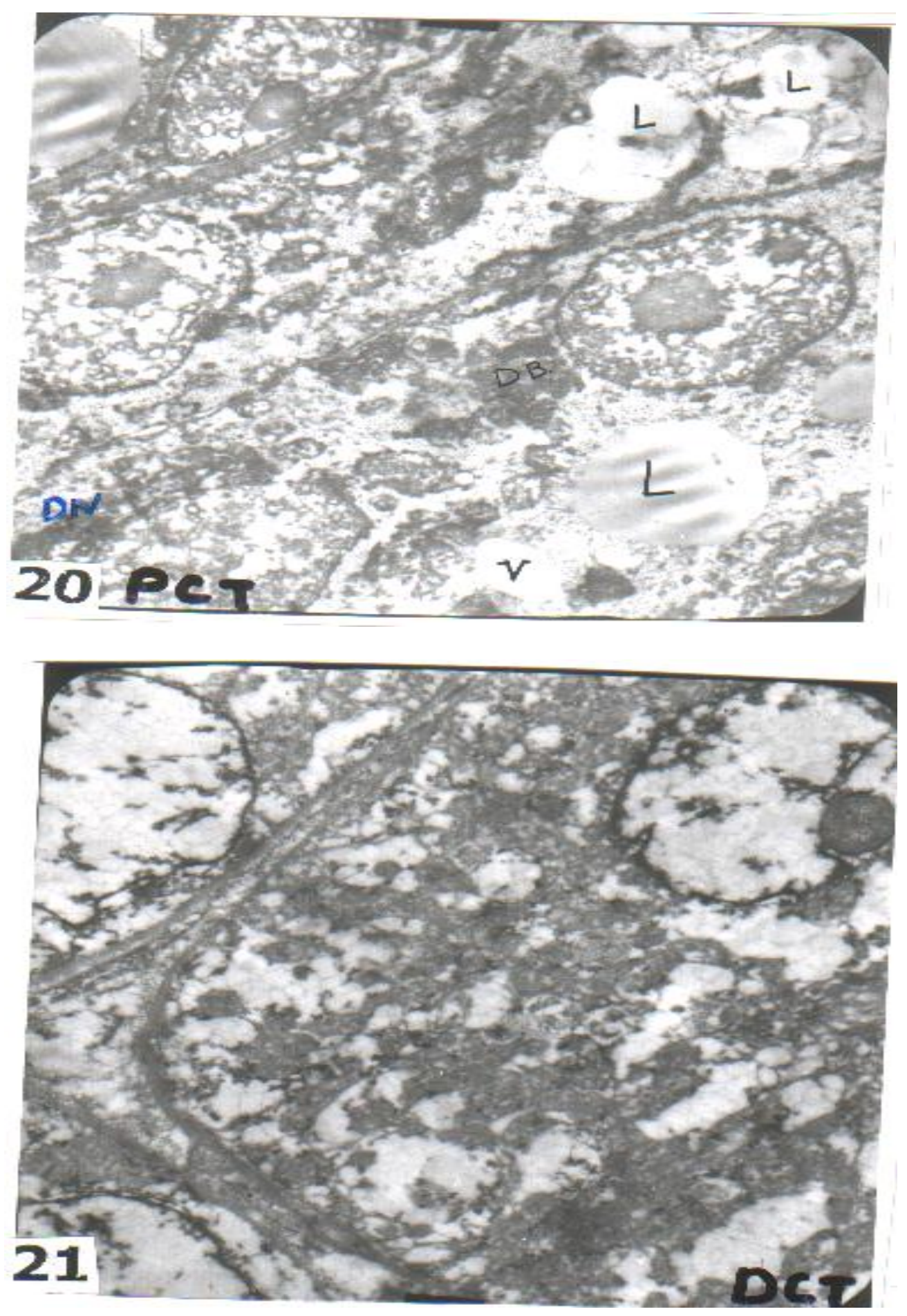

Figs 20, 21: Electron micrographs a section of 8 weeks irradiated mouse kidneys of group 2 reviled deteriorated and cytoplasm with translucent vacuoles (v). The nuclei were degenerated (DN) lack their content of heterochromatin, fat, lipid granules (L), dense bodies (DB) and damaged mitochondria with bizarre shape and tendency to fusion could be observed.

$(6000 \mathrm{X})$ 


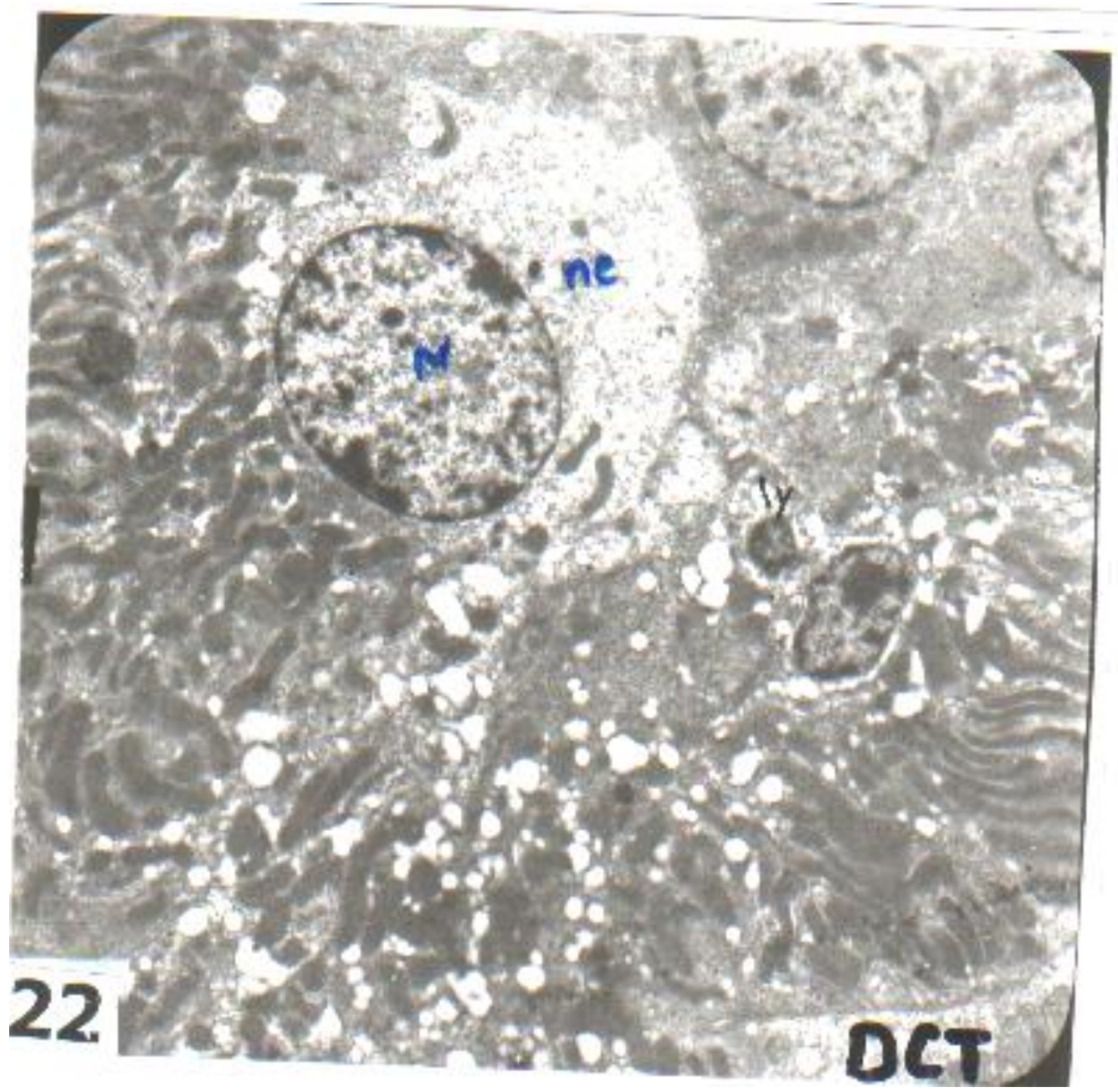

Fig22: Electron micrographs a section of 8 weeks irradiated mouse kidneys of group 2, Notice that the proximal tubule, Lost its brush border vacuolated and area of lytic cells and of necroses (ne) could be recognized. Degenerated and vacuolated cytoplasm with electron dens mitochondria could easily seen. Notice 1ry and 2ry lysosomes.

$(4000 X)$ 

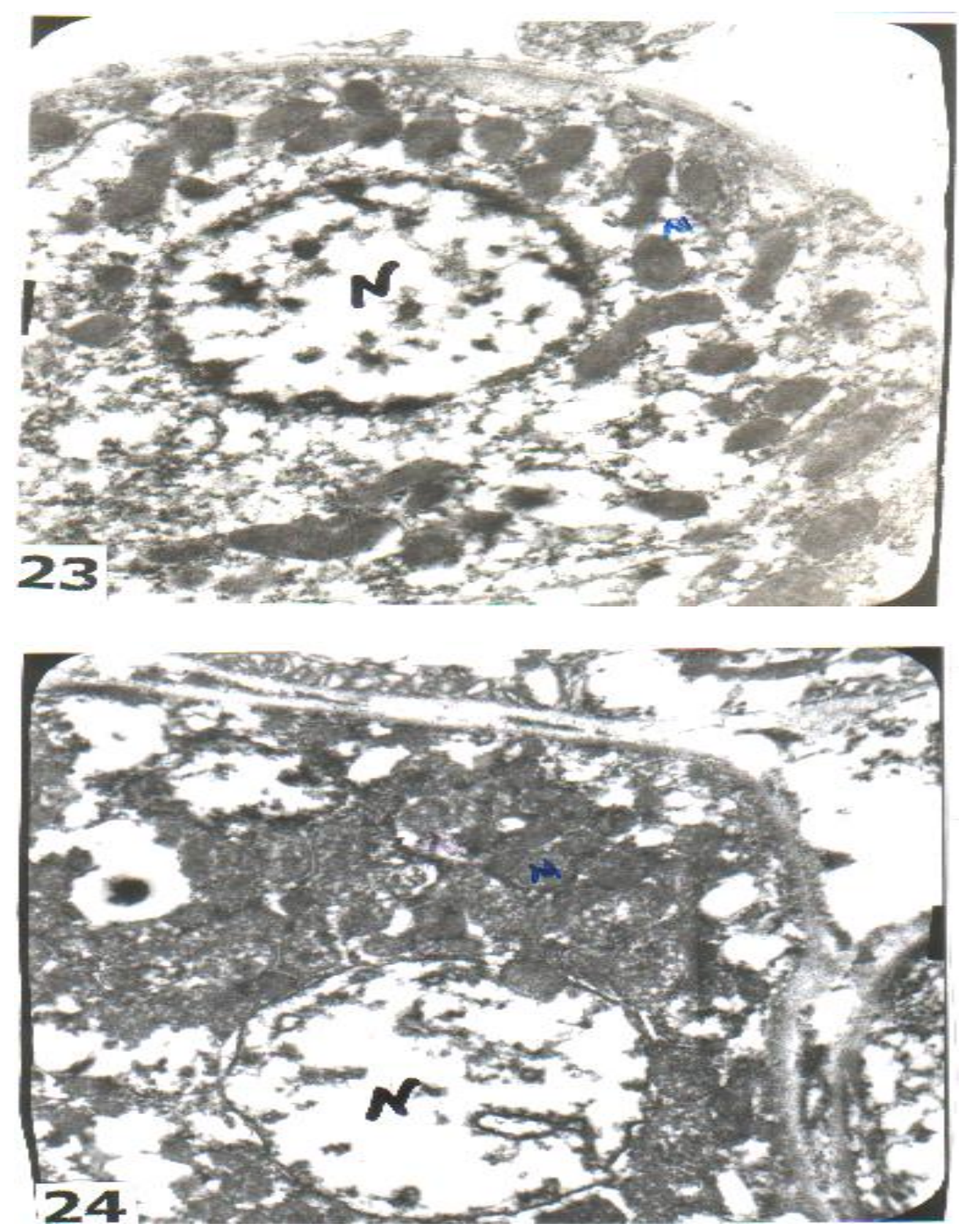

Figs 23\& 24: Electron micrographs a section of irradiated mouse kidneys of group 3, (renal proximal and distal convoluted tubules) which irradiated for 8 weeks and left 8 more weeks without exposure showed that mild amelioration could be observed. The cytoplasm is less disorganized and vacuolated, the nucleus is rounded with well detected nuclear envelope, the endoplasmic reticulum is fragmented and the lining cells of the distal tubules appear markedly rarified .The mitochondria $(\mathrm{M})$ were condensed small and electron dense.

$(6000 \mathrm{X})$ 

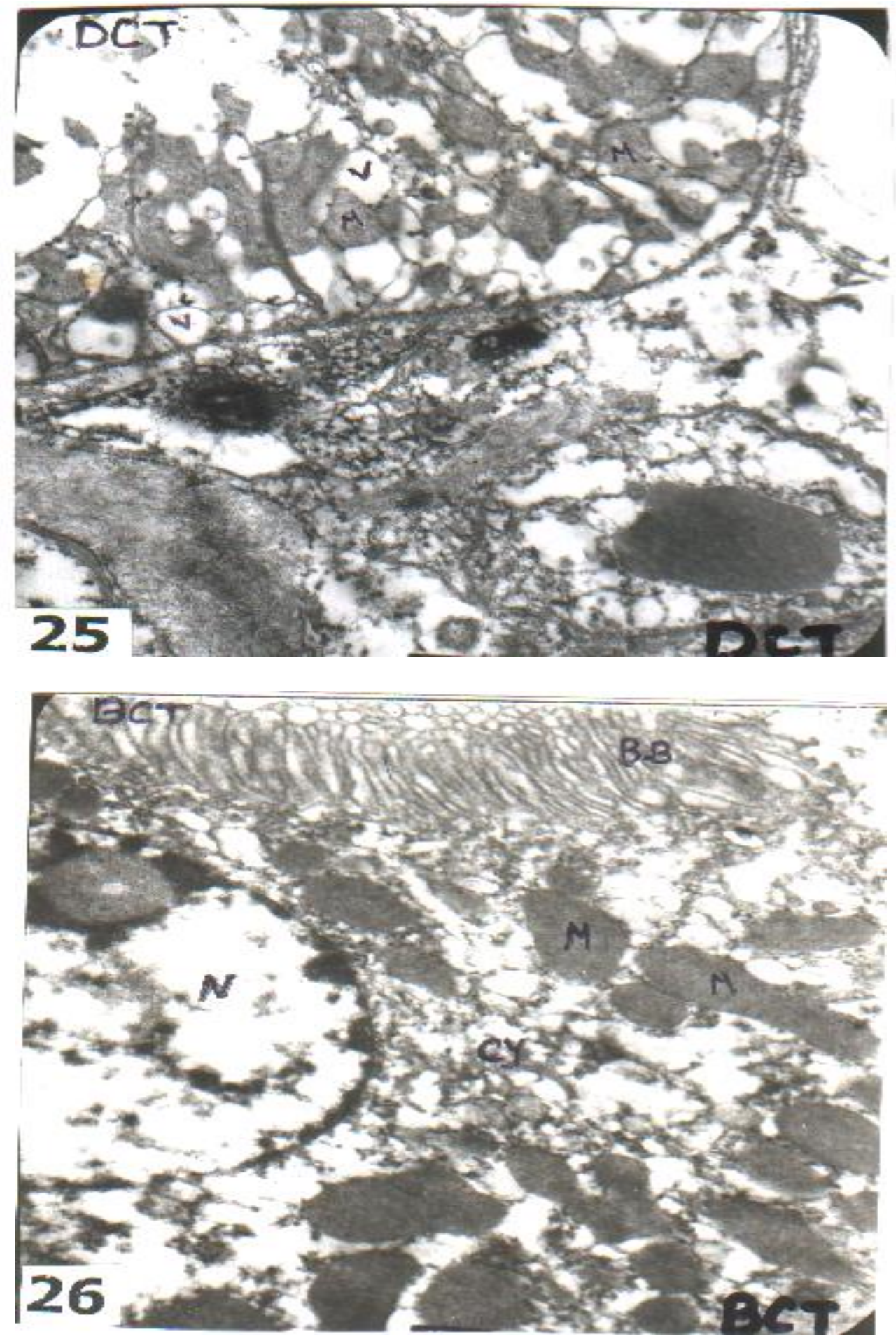

Figures 25,26 : Electron micrographs a section of irradiated mouse kidneys of group 3, showed that the distal \& proximal tubules (DCT \&BCT) slightly regain there structure .The mitochondria (M) were many, swollen and electron dense with well organized crestea the nucleus $(\mathrm{N})$ with irregular chromatin masses the ground cytoplasm lakes its organization with many vacuoles hitting the mitochondria were recognized. The brush border (BB) was easily seen. (6000 X) 

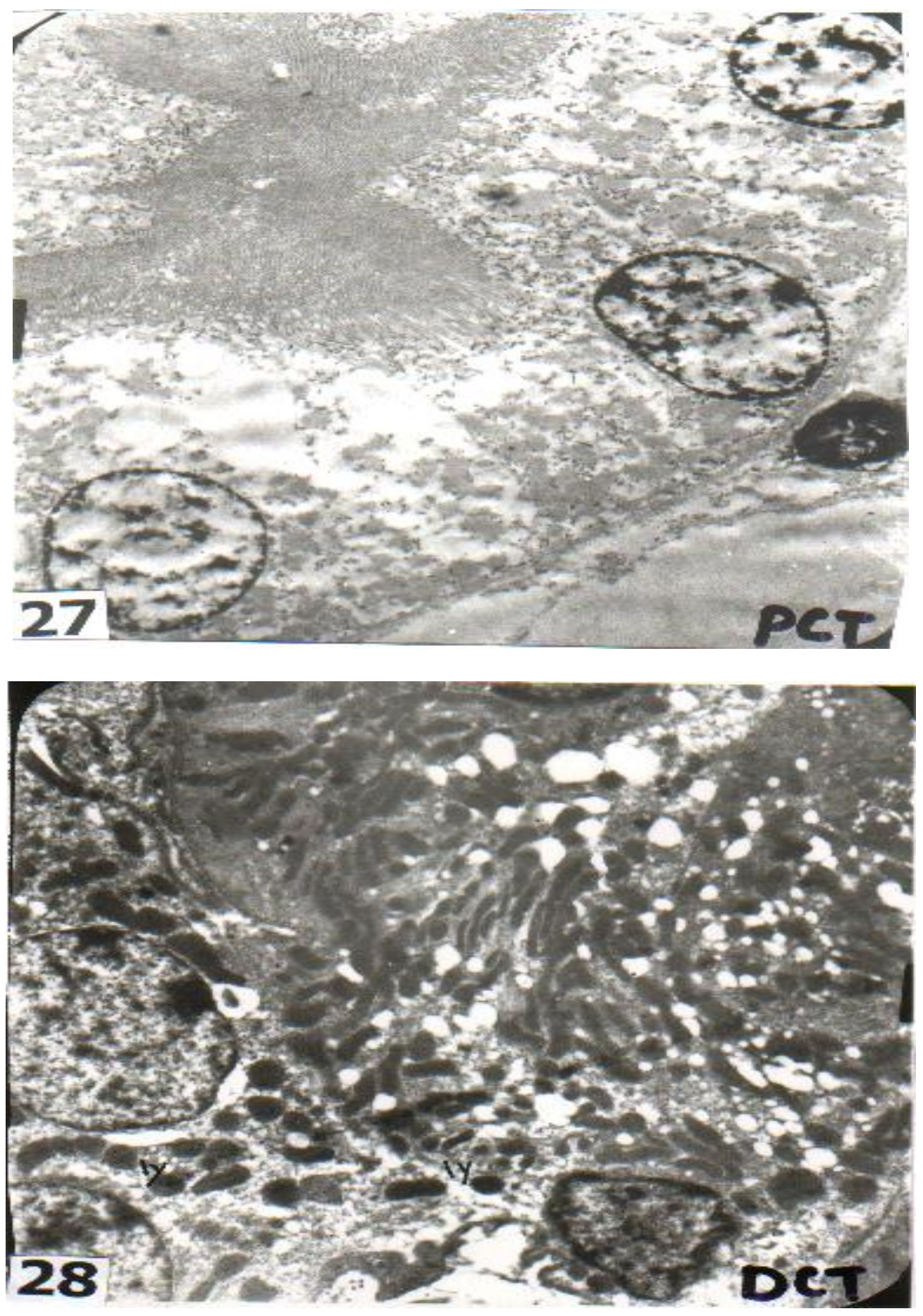

Fig 27, 28 : Electron micrographs a section of from mouse kidneys of treated animals of group 4. Notice that cells of the distal and proximal tubules retain there normality and structure; the nuclei $(\mathrm{N})$ were rounded with well-developed nuclear membrane and chromatin. The basement membranes $(\mathrm{BM})$ regain its structure with distinct brush border and precipitated plasma protein was recognized. Cells of the distal tubules were well designed with many mitochondria $(\mathrm{M})$ and healthy nucleus while the cytoplasm was still vacuolated and darkly stained in some parts than the others (1ry lysosomes (LY) could be seen in fig 28.) 

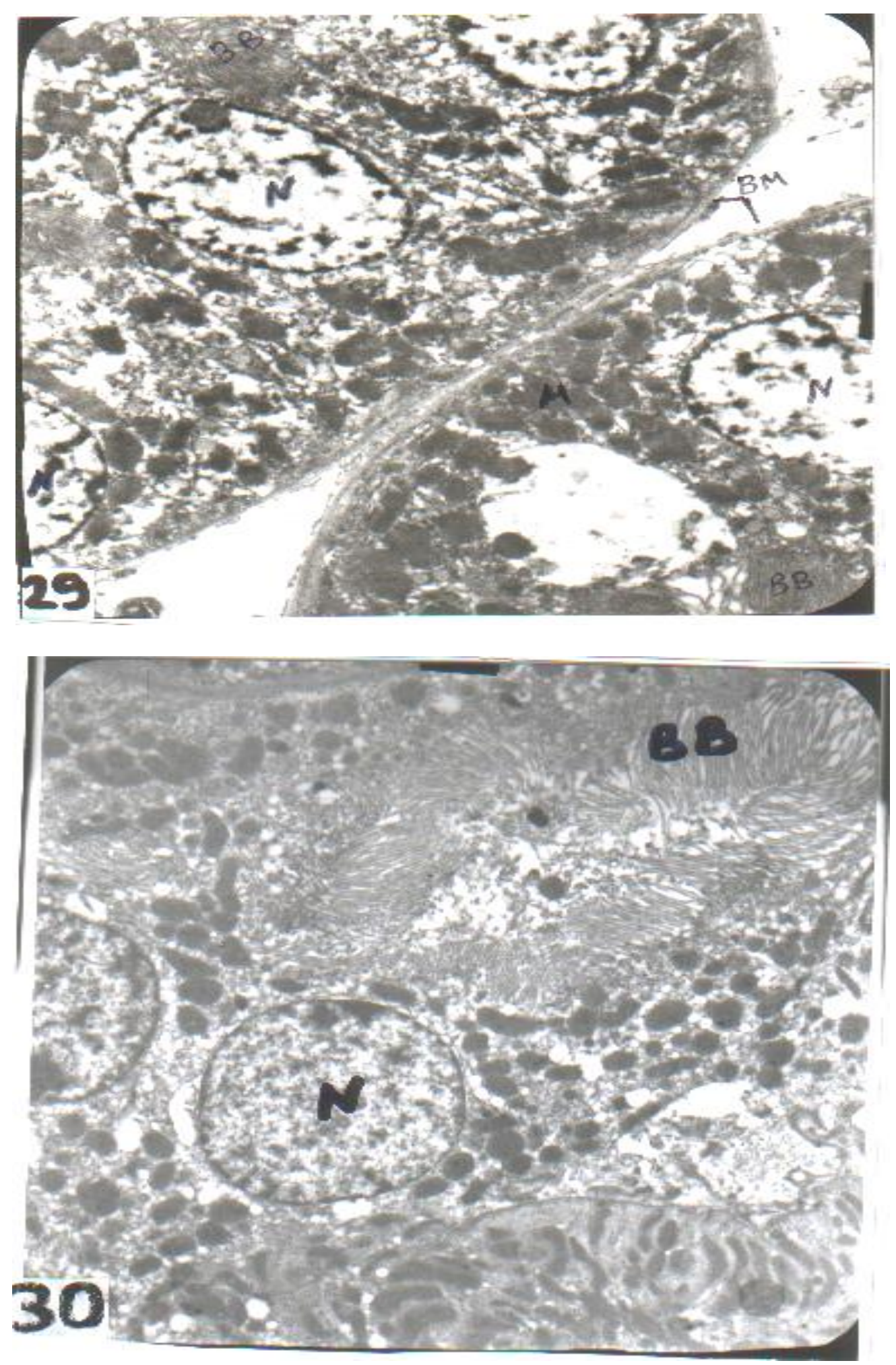


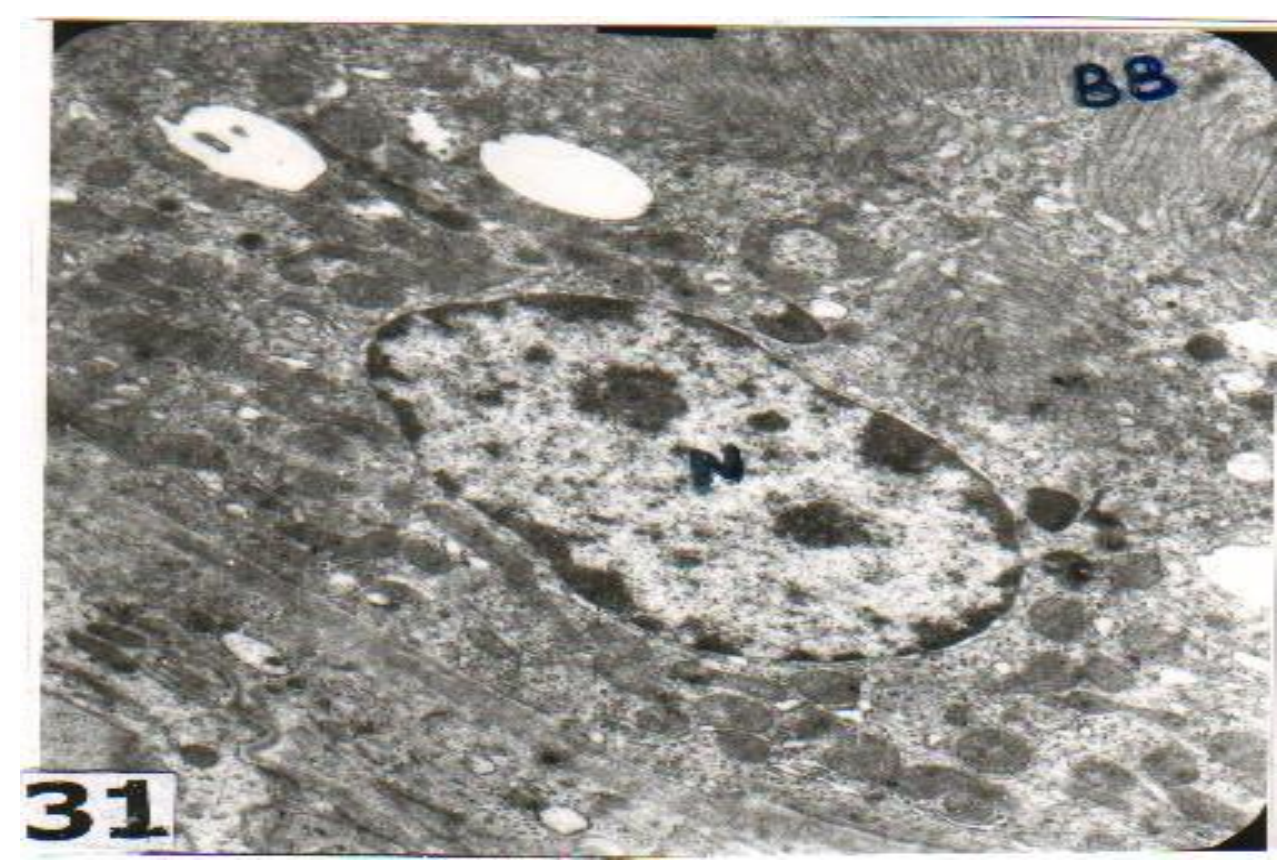

Figs 29, 30, 31 : illustrates examined sections of treated kidneys of group 5 showed that treatment of melatonin after and before irradiation helped the cells of the kidney to be more or less normal in structure. Small effects still observed and could be summarized by cytoplasmic vacuolation and myelin patches $(6000 \mathrm{X})$

\section{Discussion:}

That ionizing radiation can have serious adverse effects on people was obvious to the first experimenters 100 years ago. Exposure of mammalian cells to high-doses of ionizing radiation (IR) results in a range of tissue, cellular, and genetic defects. But, little is known of the relative cellular mechanisms and responses after low-dose exposures. Ionizing radiation, like many other hazards, can and does have detrimental health effects, including cancer, at high doses and high dose rates. There is however, considerable controversy on the health effects of low-level radiation, at or below typical natural background levels.

Weinberg, et al., (1987) stated that, There is no safe level of exposure and there is no dose of radiation so low that the risk of a malignancy is zero, the concept of what constitutes a low dose has been modified considerably over the last 50 years The biological effects of low levels of ionizing radiation, and

regulatory measures to protect people from exposure to low doses, have come in for much scrutiny in recent years.

Luckey (1991), Stated that Injury to living tissue results from the transfer of energy to atoms and molecules in the cellular structure. Ionizing radiation causes atoms and molecules to become ionized or excited. These excitations and ionizations can, Produce free radicals, Break chemical bonds, Produce new chemical bonds and crosslinkage between macromolecules, Damage molecules that regulate vital cell processes (e.g. DNA, RNA, proteins). The cell can repair certain levels of cell damage. At low doses, such as that received every day from background radiation, cellular damage is rapidly repaired. At higher levels, cell death results. At extremely high doses, cells cannot be replaced quickly enough, and tissues fail to function.

Kidney is among the most radiosensitive organ in the body. The 
tubular cells are among the most important target cells for radiation injury. That is why we select it to study the radiation effects on. The results obtained -revealed that fractionated dose of gamma radiation affects the structure of the kidney The intensity of the histological damage was more marked in the untreated irradiated group which irradiated for 8 weeks than those which are irradiated and left more 8 weeks without radiation The kidney tissue of irradiated mice showed degenerative and narcotizing changes these changes were observed in both the glomeruli and the distal and proximal tubules these finding were confirmed by Wallace (1998) , Kost et al.(2002 )and Tunez et al., (2002) .

The role of reactive oxygen species in ionizing radiation injury and the potential of antioxidants to reduce these deleterious effects have been studied in animal models for more than 50 years. Weiss and Landauer, (2000) reported that many natural antioxidants have anti-mutagenic properties that need further examination with respect to long-term radiation effects. Modulation of endogenous antioxidants, such as super oxide dismutase, may be useful in specific radiotherapy protocols. Other drugs, such as nimodipine, propranolol, and methylxanthines, have antioxidant properties in addition to their primary pharmacological activity and may have utility as radio protectors when admini stered alone or in combination with phosphorothioates. Badr et al., (1999) suggest that melatonin administration confers protection against damage inflicted by radiation when given prior to exposure to irradiation and not after, and support the contention that melat onin radioprotection is achieved by its ability as a scavenger for free radicals generated by ionizing radiation. Melatonin (Mel) is the chief secretary product of the pineal gland and has a very potent antioxidant activity, depending mainly on its capacity to act as electron donor (Tan et al., 1993 and Reiter, 1995).

Melatonin has been reported to participate in the regulation of a number of important physiological and pathol ogical processes. It has also the ability to protect the genetic material of hematopoietic cells of mice from damaging effects of acute total body irradiation. ( Koc et al. , 2002).

In vivo and in vitro, Mel has been found to protect tissues against oxida tive damage generated by a variety of toxic agents and metabolic processes, including chemotherapy-induced toxic ity Lissoni et al., 1997 and ischemiareperfusion injury in stomach, liver, and brain (Sewerynek, et al, 1996, De Lastra, 1997, and Konturek ,1997). More pertinently, Mel has recently been found to protect against adriamycininduced nephrotoxicity (Montilla, et al., 1997). Mel is widely available, relati vely free of side effects, rapidly active after oral administration, and commonly used in humans in the treatment of insomnia (.Brzezinski, 1999)

The mechanisms of the radioprotective effects of melatonin seem to consist particularly of its scavenging $\mathrm{OH}$ and other free radicals and reactive oxygen intermediates, and its ability to modify the activity of enzymes partici pating in oxidative stress. Besides the obvious ant oxidative mechanisms by which melat -onin functions in the protection of DNA, it also may influence DNA repair enzymes directly and stimulate intracellular signals indir ectly for the activation of genes responsible for protein synthesis related to DNA repair. These latter processes deserve more extensive investigation in relation to melatonin (Kundurovic and Mornja -kovic, 1 992, and, Benot, et al., 
1998). Lipids (Reiter, 1995, and Siu and Reiter, 1999) and proteins (Kaya et al., 1999). The evidence summarized here in, related to radio-protective effects of melatonin against cellular damage caused by oxidative stress, make this molecule a potential supplement that should be considered in the treatment or co-treatment in situations where the effects of ionizing radiation are to be minimized (e.g., during routine therap ies, in occupational settings where accidental exposure may occur, during space travel, or after nuclear accidents, and where high radiation persists (Mayerly et al., 2000).

There is some evidence for the protective role of melatonin against radiation-induced damage in the endocrine system. It was observed that pretreatment with melatonin partially reversed histo-enzymological changes in rat thyroid gland caused by the exposure to 8 Gy of gamma-radiation (Kundur ovic and Scepovic, 1989).

In another study that used morphometric parameters, melatonin was shown to decrease the height of the thyroid follicular cells and nuclear volume of these cells obtained from 8 Gyirradiated rats (Kundurovic and Mornjakovic, 1992). Melatonin treatm ent also inhibited the effect of gammairradiation at a dose of $8 \mathrm{~Gy}$ on several morphometric characteristics of the seminiferous tubules in rats (Mornj akovic et al., 1991) Similarly, the treatm -ent of rats for 2 weeks with melatonin at a daily dose of $0.2 \mathrm{mg}$ significantly decreased what the authors referred to as the nuclear and cytoplasm surface of Leyding cells in rats exposed to $8 \mathrm{~Gy}$ radiation, (Mornjakovic et al., 1998)

Results obtained from this study stated that melatonin administration after and during irradiation helps the protection and recovery of the kidney cells while contentious treatment after irradiation for a suitable time helps the cells to become normal and healthy these finding were in agreement with Lopez-Burillo et al., (2003), Tan et al., (2003) and Kaptanoglu et al., (2003). The findings raise the possibility of melatonin being considered as an effective radio protective agent In conc -lusion, melatonin effectively protects kidney cells in mice against oxidative damage caused by gamma radiation may be of value as a supplement in patients suffering from kidney frailer related to gamma ray exposure.

\section{References}

1. Badr FM, EI Habit OH, Harraz MM. (1999): Radio protective effect of melatonin assessed by measuring chromosomal damage in mitotic and meiotic cells. Mutat Res. Aug 18; 444(2):367-72.

2. Benot $S$, Molinero $P$, Soutto $M$, Goberna R, Guerrero JM. (1998):

Circadian variations in the rat serum total antioxidant status: correlation with melatonin levels. J Pineal Res. Aug; 25(1):1-4.

3. Brzezinski, A., (1997): Melatonin in humans. N Engl J Med 336: 1186-1195.

4. De Lastra, CA, Cabeza J, Motilva V, and Martín MJ. , (1997): Melatonin protects against gastric ischemiareperf usion injury in rats. J Pineal Res 23: 47-52

5. Donaldson SS, Moskowitz PS, Evans JW, Fajardo LF. (1984) : Protection from radiation nephropathy by WR2721. Radiat Res Feb; 97(2): 414-23

6. Geraci JP, Jackson KL, Mariano MS, Michieli BM ( 1990) : Kidney and lung injury in irradiated rats protected from acute death by partial-body shiel ding. Radiat Res Apr; 122(1): 95-100.

7. Halliwell B, Aruoma OI. DNA, (1991): Damage by oxygen-derived species. FEBS Lett 281:9-19

8. Kaptanoglu E, Palaoglu S, Demirpence E, Akbiyik F, Solaroglu I, Kilinc A (2003): Different responsiveness of central nervous system tissues to oxidative conditions 
and to the antioxidant effect of melatonin. J Pineal Res 34 (1) :32-5 .

9. Kaya H, Delibas N, Serteser M, Ulukaya E, Ozkaya O, (1999) : The effect of melatonin on lipid peroxida tion during radiotherapy in female rats. Strahlenther Onkol. Jun; 175(6):285-8.

10. Kellerer AM, Walsh L, Nekolla EA. , (2002) : Risk coefficient for gamma rays with regard to solid cancer. Radiat Environ Biophys Jun;41(2):113-23

11. Konturek, PC, Konturek SJ, Brzozowski T, Dembinski A, Zembala M, Mytar B, and Hahn EG. (1997) Gastroprotective activity of melatonin and its precursor, Ltryptophan, against stress-induced and ischemia-induced lesions is mediated by scavenge of oxygen radicals. Scan $J$ Gastoenterol32:433-438,

12. Koc M, Buyukokuroglu ME, Taysi S.( 2002) : The effect of melatonin on peripheral blood cells during total body irradiation in rats. Biol Pharm Bull. May;25(5):656-7.

13. Kost S, Dorr W, Keinert K, Glaser FH, Endert G, Herrmann T. (2002) : Effect of dose and dose-distribution in damage to the kidney following abdominal radiotherapy. Int $\mathrm{J}$ Radiat BiolAug;78(8):695-702.

14. Koultcavenia, Ekaterina V., (1998) Influence of low-level laser radiation on kidney functions Novosibirsk Research Institute of TuberculosisProc. SPIE Vol.3569 , p.70 -74, Effects of LowPower Light on Biological Systems IV, Giovanni F. Bottiroli; Tiina I. Karu; Rachel Lubart; Eds.

15- Kundurovic $\mathbf{Z}$, Mornjakovic $\mathbf{Z}$. (1992. ): Morphometric characteristics of thyroid cells in irradiation-stressed rats treated with pinealectomy and melatonin. Med Arh 46:9-10,

16- Kundurovic Z, Scepovic M. (1989): Histoenzymological reactions of the thyroid gland in irradiated and previously melatonin-treated irradiated rats. Acta Med Iugosl 43:337-347, .

17- Lindholt JS. : Radiocontrast induced nephropathy( 2003 ) Eur J Vasc Endovasc Surg.;25(4):296-304.
18- Lissoni， P， Tancini G， Barni S, Paolorossi F, Ardizzoia A, Conti A, and Maestroni G. (1997) :Treatment of cancer chemotherapy-induced toxic ity with the pineal hormone melatonin. Support Care Cancer 5: 126-129.

19- Luft, J.H. (1961) : Improvement in epoxyresin embedding methods. Biophys. Biochem. Cytol. 9: 409- 414.

20- Lopez-Burillo S, Tan DX, RodriguezGallego V, Manchester LC, Mayo JC, Sainz RM, Reiter RJ.: Melatonin and its derivatives cyclic 3-hydroxymelatonin, N1-acetyl-N2-formyl-5-methoxykynu ramine and 6-methoxy elatonin reduce oxidative DNA damage induced by Fenton reagents. J Pineal Res 2003 Apr ;34 (3):178-84

21- Luckey, T.D., (1991)."Radiation hormesis", CRC Press

22- Mallory, Frank B. (1944): Pathological Technique, Philadelphia : W.B. Saunders .

23- Maigorzata Karbownikand and Russel J. Reiter,(2000) :Antioxidative Effects of Melatonin in Protection Against Cellular Damage Caused by Ionizing Radiation Proceedings of the Society for Experimental Biology and Medicine 225:9-22

24- Maisin JR(1982): [Chemical protec tion against the long-term effects in mice exposed to supralethal doses of $\mathrm{X}$ rays] C R Seances Soc Biol Fil;176 (1):68-72

25- Mayerly Nava, Freddy Romero, Yasmir Quiroz, Gustavo Parra, Lizette Bonet, and Bernardo Rodríguez- Iturbe November (2000) : Melatonin attenuates acute renal failure and oxidative stress induced by merc uric chloride in rats Am J Physiol Renal Physiol Vol. 279, Issue 5, F910-F918,

26- Montilla, P, Tunez I, Muñoz MC, Lopez A, and Soria JV. , (1997): Hyperlipidemic nephropathy induced by adriamycin: effect of melatonin administration. Nephron 76: 345-350

27- Morgan WF, Day JP, Kaplan MI, McGhee EM, Limoli CL. , (1996). Genomic instability induced by ioniz ing radiation. Radiat Res 146:247-258 . 
28- Mornjakovic Z, Scepovic M, Kundurovic Z (1991) : Morphometric aspects of seminiferous tubules in rats treated with melatonin and whole body irradiation. Med Arh 45:9-10.

29- Mornjakovic Z, Alicelebic S, Bilalovic N, Susko I.( 1998.) : Morphometric characteristics of Leydig cells after total irradiation of rats treated with melatonin. Med Arh 52:183-184.

30- Parlakpinar H, Sahna E, Ozer MK, Ozugurlu F, Vardi N, Acet A. (2002): Physiological and pharmacological concentrations of melatonin protect against cisplatin-induced acute renal injury. J Pineal Res. Oct;33(3):161-6.

31- Parsons, P.A., (1994), : "Radiation hormesis: An evolutionary expectation based upon exposure to background radiation", BELLE Newsletter 3, 9.

32- Reiter, RJ. , (1995) :The role of the neurohormone melatonin as a buffer against macromolecular oxidative damage. Neurochem Int 27: 453-460.

33- Reynold, A.S. (1963) : The use of lead citrate at high $\mathrm{pH}$ as an electron opaque stain in electron microscopy . J Cell Bio. 17: 208-210.

34- Rojas A, Stewart FA, Soranson JA, Smith KA, Denekamp J. (1986): Fractionation studies with WR-2721: normal tissues and tumour. Radiother Oncol May;6(1):51-60.

35- Safwat A, Nielsen OS, el-Badawy S, Overgaard J. (1995) : Late renal damage after total body irradiation and bone marrow transplantation in amouse model: effect of radiation fractionation. Eur J Cancer. Jun;31A (6): 987-92.

36- Sewerynek, E, Reiter RJ, Melchiorri D, Ortiz GG, and Lewinski A. ,(1996) : Oxidative damage, in the liver induced by ischemia-reperfusion: protection by melatonin. Hepatogastro -enterology 43: 898-905.

37- Singh SP, Jayanth VR, Chandna S, Dwarakanath BS, Singh S, Adhikari JS, Jain V. (1998):Radioprotective effects of DNA ligands Hoechst-33342 and 33258 in whole body irradiated mice. Indian J Exp Biol Apr;36(4): 375-84
38- Siu AW, Reiter RJ, To CH. (1999) : Pineal indolamines and vitamin E reduce nitric oxide-induced lipid peroxidation in rat retinal homogenates. J Pineal Res 27:122-128.

39- Tan DX, Hardeland R, Manchester LC, Poeggeler B, Lopez-Burillo S, Mayo JC, Sainz RM, Reiter RJ. (2003) (Mechanistic and comparative studies of melatonin and classic antioxidants in terms of their interac tions with the ABTS cation radical).J Pineal Res May;34(4):249-59.

40- Tan, DX, Chen LD, Poeggeler B, Manchester LC, and Reiter RJ. , (1993 ) :Melatonin: a potent, endoge nous hydroxyl radical scavenger. Endocrine $J$ 1: 57-60.

41- Tan DX, Manchester LC, Reiter RJ, Plummer BF, Hardies LJ, Weintraub ST, Vijayalaxmi Shepherd AMM. (1998) :A novel melatonin metabolite, cyclic 3-hydroxymelatonin: A bioma rker of in vivo hydroxyl radical genera tion. Biochem Biophys Res Commun 253:614-620,

42- Tunez L, Munoz MC, Feijoo-Lopez AL, Valdvira E, Bujalance-Arenas L, Montilla P. (2002): Effect of melat onin on hyperlipidemic nephrop -athy under constant light exposure.J Physiol Biochem;58(2):109-14 Jun

43- van Kampen M, Eble MJ, Krempien R, Jensen K, Aydenitz B, Metzger M, Hensley F, Haufe S, Amelung F, Wallwiener $\mathbf{D}$, Wannenmacher $\mathbf{M}$ (2003.): Influence of irradiated volume on ureteral injury after intraop -erative radiation therapy: experimental study in dogs. Radiology. 2003 Jul;228(1):13943. Epub May15.

44- Wallace SS (1998): Enzymatic proce ssing of radiation-induced free radical damage in DNA. Radiat Res 150:S60S79,.

45- Weinberg, JM, Harding PC, and Humes HD. , ( 1987) :Mitochondrial bioenergetics during the initiation of mercuric chloride-induced renal injury. J Biol Chem 257: 60-67

46- Weiss JF, Landauer MR.( 2000) :Radioprotection by antioxidants Ann N Y Acad Sci; 899:44-60 


\title{
التأثير المضاد للأكسدة للميلاتونين كمادة واقية من ضرر التعرض الإقياعي الإشعاعي للكلية
}

\section{(دراسات ميكروسكوبية بالميكروسكوب الضوئي والإكتروني)}

\author{
د/ هناء فتحى محمود

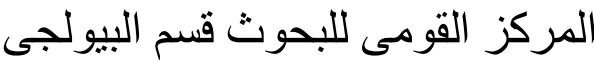

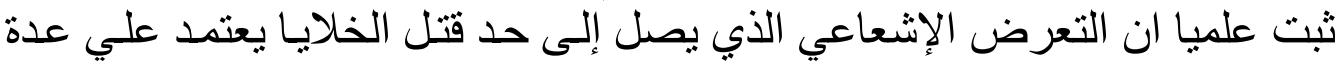

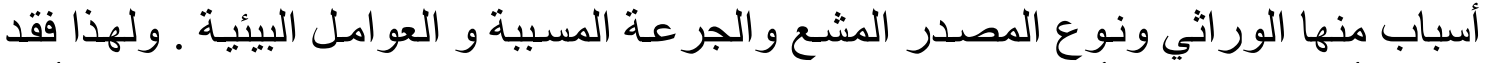

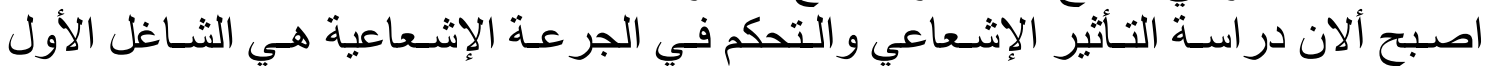

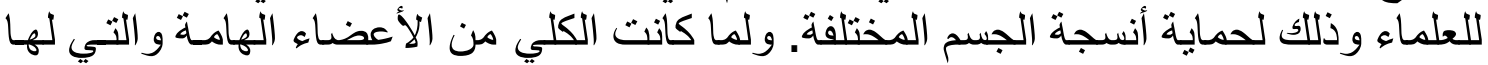

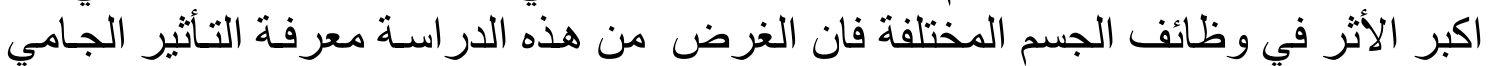

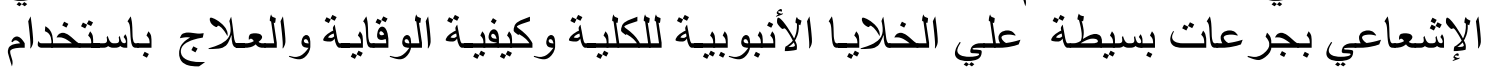

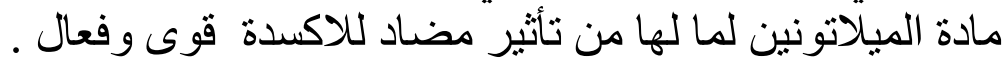

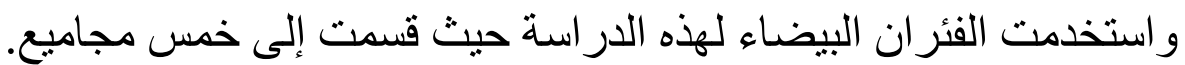

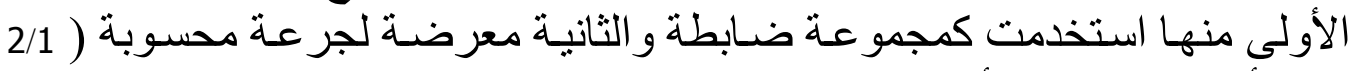

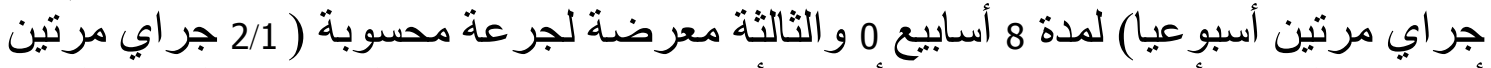

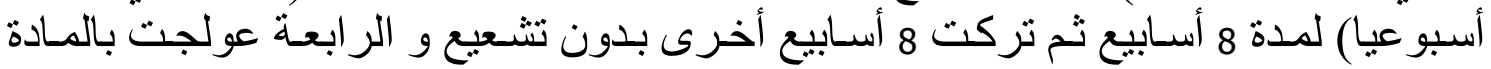

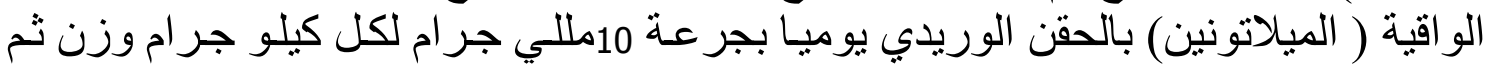

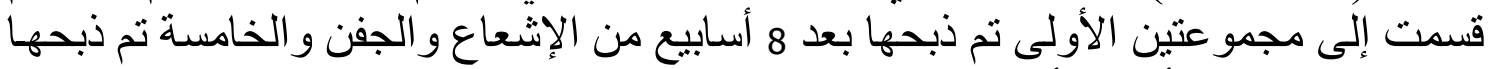

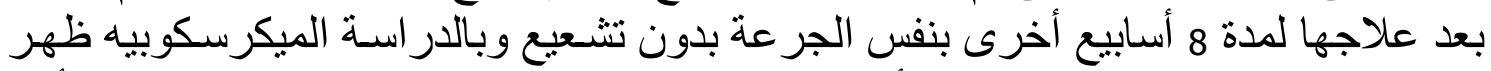

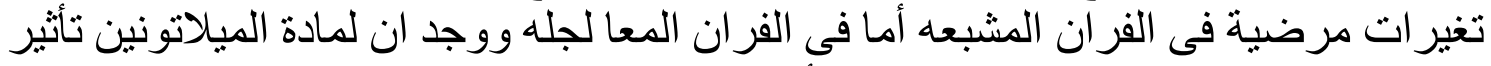

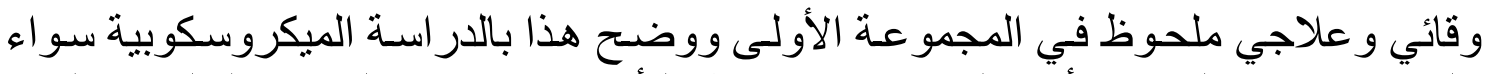

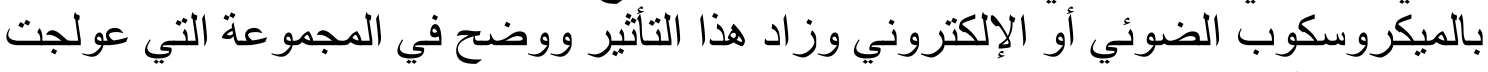

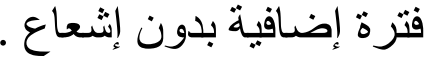

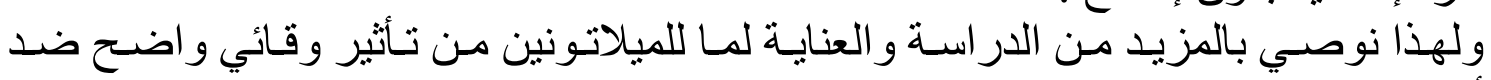
أضرار الإشعاع النسيجية للكلية. 